\title{
Influence of Perceived Risk Dimensions on e-Shopping Behavioural Intention among Women-A Family Life Cycle Stage Perspective
}

\author{
Raman Amirtha ${ }^{1, *(\mathbb{D}, \text { V. J. Sivakumar }}{ }^{1}$ and Yujong Hwang ${ }^{2,3}$ \\ 1 Department of Management Studies, National Institute of Technology, Trichy 620015, India; vjs@nitt.edu \\ 2 School of Accountancy \& MIS, DePaul University, Chicago, IL 60604, USA; yhwang1@depaul.edu \\ 3 Kyung Hee University, Yongin-si, Gyeonggi-do 17104, Korea \\ * Correspondence: amirthamba2008@yahoo.co.in
}

Received: 10 July 2020; Accepted: 9 November 2020; Published: 20 November 2020

check for updates

\begin{abstract}
The relationship between perceived risk and behavioral intention (BI) in e-shopping, based on family life cycle (FLC) stages, has been analyzed in this work. Although FLC stages are considered to have a better predictive ability than age, few e-shopping studies have concentrated on understanding its effects. This study, as a pioneering effort, has divided Indian women based on nine FLC stages and has studied the role of ten dimensions of perceived risk on BI to shop online across each life cycle stage. Results show that different facets of risks had distinct effects on purchase behavior among women belonging to different FLC stages. In effect, this study shows the importance of splitting people based on FLC stages in e-marketing and its value in making marketing decisions.
\end{abstract}

Keywords: online shopping; family life cycle (FLC) stages; perceived risk; behavioral intention; India; women; socio-demographics

\section{Introduction}

There has been phenomenal Internet penetration in India in recent years, from just $4 \%$ in 2007 to nearly $50 \%$ in 2020 [1]. This has led to a substantial increase in e-retail sale. The e-retail market itself is estimated to grow from US\$24 billion in FY 2019 to US\$98 billion in FY 2024 [2]. The sector is expected to continue growing and attracting attention of e-retailers across the globe. However, at present, $80 \%$ of the population who shop online are young people (below 35 years) while other consumer segments' acceptance of e-shopping as a purchasing channel is low. Thus, the percentage of online sales in terms of total retail sales was only $1.6 \%$ in India, versus over $15 \%$ for China and around $14 \%$ globally and hence e-retail is considered to be still in a nascent stage in India [3]. In order to increase the online sales, it is important to make middle aged and older population also to shop online. Ignoring this fact, most extant e-shopping research studies in India have concentrated on understanding the motivation of young people for e-shopping (meta-analysis by $[4,5]$ ), rather than identifying the barriers that prevent others from shopping online [6-8], which is the purview of current study.

Perceived risk is considered the most important psychological state that negatively influences one's e-shopping behavior as shown by many studies [9-18], meta-analysis by [19]. However, most of the earlier studies have been conducted in developed countries $[15,20,21]$. The risk perception towards any new technology is found to be high in developing countries, especially in countries like India with a collectivistic culture [9,12,22]. People from countries like India are risk-averse and hence are slow in the adoption of any technology. Hence, e-shopping researchers have noted that to make these people shop online, it is important for retailers to focus on reducing risks rather than concentrating on benefits when setting up their online presence [12]. E-shopping researchers have emphasized that 
there exists a knowledge gap on the factors that act as barriers of adoption of e-shopping technology in developing countries [5,9,23-26]. Moreover, while several studies have highlighted the importance of considering the multi-dimensionality of perceived risk [15,27], few studies have been conducted taking the various dimensions into account $[6-8,10,28]$. Studies that have assumed perceived risk to be a uni-dimensional construct have observed insignificant effect of perceived risk on behavioral intention (BI) in collectivistic countries; they have reported that it is important to further disintegrate the risk construct to gain better understanding [16,29]. Hence this study considers risk as a multi-dimensional (ten) construct (Table 1) and studies the impact of various risk perceptions on e-shopping behavioral intention (BI) in the Indian context.

Table 1. Construct definitions.

\begin{tabular}{|c|c|}
\hline Construct & Definition \\
\hline \multicolumn{2}{|r|}{ Perceived Risk Dimensions } \\
\hline Performance & The probability that a product might not perform as expected \\
\hline Security & The possibility that the product will cause financial loss \\
\hline Time-loss & The possibility that a purchase will take too long or waste too much time \\
\hline Social & $\begin{array}{l}\text { Concern with an individual's ego and the effect that a purchase will have on the } \\
\text { opinions of reference groups }\end{array}$ \\
\hline After-sale & $\begin{array}{l}\text { Potential loss of after-sales service associated with product problems, commercial } \\
\text { disputes, and service guarantee. }\end{array}$ \\
\hline Source & $\begin{array}{l}\text { Concern over whether the prospective shopper can trust the online vendors and feel } \\
\text { comfortable in doing business with them. }\end{array}$ \\
\hline Psychological & $\begin{array}{l}\text { Concern about the psychological discomfort and tension that may arise because of } \\
\text { online shopping }\end{array}$ \\
\hline Privacy & $\begin{array}{l}\text { Potential loss of control over personal information when this is used without } \\
\text { permission. }\end{array}$ \\
\hline Delivery & $\begin{array}{l}\text { Concern about not receiving the product on time, long delivery time, or product being } \\
\text { damaged during delivery. }\end{array}$ \\
\hline Physical & A potential threat to an individual's safety, physical health, and wellbeing \\
\hline \multicolumn{2}{|r|}{ Behavioral Intention } \\
\hline $\begin{array}{l}\text { Behavioral } \\
\text { Intention }\end{array}$ & $\begin{array}{c}\text { The degree to which a person has formulated conscious plans to shop or not shop } \\
\text { online in the future. }\end{array}$ \\
\hline
\end{tabular}

Researchers have noted that to better understand the effect of perceived risk on BI, it is crucial to consider the moderating roles of various socio-demographic factors (meta-analysis by [30]). Perception towards risk is dependent on an individual's socio-demography, culture, and traits. People with different socio-demographic and cultural backgrounds encounter different situations in life [8]. Different types of risks are formed with respect to a particular situation encountered by an individual [31-33]. Moreover, time and psychological pressures encountered at different situations have been found to have a significant effect on risk perceptions, and the corresponding risk aversion levels also differ [34,35]. Past researchers have investigated the effect of various socio-demographic factors on perceived risk. However, studies that focus on understanding the differences in e-shopping behavior based on family life cycle (FLC) stages are limited [8,36-38]. There is a strong evidence from past literature that most situational and behavioral changes in life happen due to the FLC stages of an individual rather than his/her age. Changes in FLC stages result in differences in an individual's financial, time and psychological pressures and involvement with purchases [39-45]. Against this backdrop, we expect that there would be differences in the perceptions of risk dimensions and their interplay with BI towards e-shopping sites, as an individual transcends the various FLC stages. 
This study addresses two potential segments that are often ignored in e-shopping studies. First, most e-shopping studies on perceived risk are conducted among young people, while the pattern of risk perception among the middle-aged or older adults often considered lucrative market segments with higher disposable income- - has been least explored [46-48]. For e-shopping to expand and prosper, it is important to concentrate on people of all ages and at different stages of life [5,36]. Given that e-shopping is an integral part of today's economy, understanding the e-shopping behavior across all age groups becomes important, as the adoption of technology by older adults plays a vital role in economic development [49]. Hence to understand the effect of different demographic variables on online behavior, a further split age-based research on technology adoption is essential $[26,31,50]$. This study acknowledges that there are barriers that hinder people of different ages from shopping online and explores this further.

Another potential segment is women e-shoppers. Fewer women are online in India than in other BRIC countries. The dearth of studies on e-shopping behavior among Indian women has also been an outcome of the nascency of e-commerce in India [51]. Women perceive higher risks in e-shopping than men $[16,26,52]$ especially in developing countries like India [21,51]. Given that in most cultures, women assume the responsibility of household shopping and purchase decisions [53-55] and FLC stages have a greater effect on women than men [56], there is a need to explore the role of perceived risk in deterring Indian women of different FLC stages from participating in e-shopping activities. In addition, women are identified to spread word of mouth regarding their shopping experience than men. Hence the ability of women to attract more customers towards online shopping sites is higher than men. In addition, at the time of purchase, men are more direct and only buy at the time they need something. On the other hand, women tend to try more items than men and are more likely to make impulse purchases. Hence by targeting women it is possible to increase online sales, in-turn profit. Moreover, young women are more inclined towards e-shopping and there are many studies that have analyzed the e-shopping behavior of this section of the young population. Our study focuses on married women, i.e., women who are a part of a marital family, with and without children, and analyses the changes in their perception of e-shopping risk, which in turn, affects their BI to shop online. Since risk perception toward new technology negatively influences e-shopping behavior, and the problem is particularly bad in developing countries like India with collectivistic cultures, it pays off to try to better understand how risk perceptions influence e-shopping behavior to mitigate the problem. There are large individual differences in perceived risk, and to better understand individual factors behind risk perceptions, the current study employs the FLC.

\section{Objectives of the Study}

This study, as a pioneering effort, attempts to fill the knowledge gap in the area of e-commerce adoption, identified through a search of literature, by understanding the effect of different dimensions of perceived risk on e-shopping purchase intention among Indian women of different FLC stages. To operationalize perceived risk, the study uses the theory of perceived risk (TPR) proposed by [57]. The theory states that a customer, while buying any product would perceive some amount of risk. They believe that their purchasing actions would lead to consequences that cannot be anticipated with anything approximating certainty, and some of the consequences are likely to be unpleasant. Hence, the consumer's choices are divided into risk-increasing or risk-decreasing behavior. Bauer initially proposed perceived risk but did not include specific types. Later researchers have considered perceived risk as a combination of several dimensions [58]. Under the new Internet environment, as scholars adjusted the model according to the development of technology, economy and society, more dimensions were identified. However, there is no agreement on the dimensions of perceived risk.

Researches on perceived risk have divided it into different dimensions according to different situations. Not all dimensions of perceived risk have been found to have significant effects on consumer's behavior [59]. Thus, there is a need to examine the effect of different dimensions of perceived risk on a consumer's behavior in sharing economy [27]. 
In this study, we have considered ten dimensions of perceived risk (Table 1)-financial risk, performance risk, time-loss risk, privacy risk, delivery risk, social risk, after-sales service risk, source risk, psychological risk, and physical risk [60], and have identified the risk dimensions affecting e-shopping behavioral intention among women of different FLC stages. To operationalize the FLC stages, a customized Indian FLC stages model comprising nine FLC stages, proposed by [36] has been used (Table 2).

Table 2. Classification of stages of family life cycle.

\begin{tabular}{|c|c|c|}
\hline No. & Stage & Operational Definition \\
\hline \multicolumn{3}{|c|}{ Early LC Stages } \\
\hline 1 & Newly Married (NM) & Married families without children \\
\hline 2 & Expecting Parents (EP) & $\begin{array}{l}\text { Families with pregnant women bearing child 0-9 } \\
\text { months }\end{array}$ \\
\hline 3 & Families with Infants (FN(I)) & Families with youngest child below 3 years \\
\hline 4 & Families with Preschool Children (FN(PC)) & Families with youngest child $3-5$ years \\
\hline 5 & Families with School Children (FN(SC)) & Families with youngest child $6-12$ years \\
\hline \multicolumn{3}{|c|}{ Later LC Stages } \\
\hline 6 & Families with Teenage Children (FN(TC)) & Families with youngest child $13-18$ years \\
\hline 7 & Families with Adult Dependents (FN(AD)) & $\begin{array}{l}\text { Families with youngest child } 18 \text { years-until they are } \\
\text { employed }\end{array}$ \\
\hline 8 & Families with Adult Independents (FN(AI)) & $\begin{array}{l}\text { Families with youngest child employed-until they } \\
\text { leave the parental nest }\end{array}$ \\
\hline 9 & Empty Nest and Solitary Survivors (EN\&SS) & Families with no children (employed and retired) \\
\hline
\end{tabular}

Furthermore, the researchers that applied TPR to understand e-shopping risk perception highlighted that gender plays a crucial role in affecting e-shopping risk perception; women are identified to be risk-averse than men $[61,62]$. Hence, this study attempts to test how the perceived risk perception influence Indian women's e-shopping behavior as they transcend through different FLC stages.

With this background, we arrive at the following research questions (Figure 1).

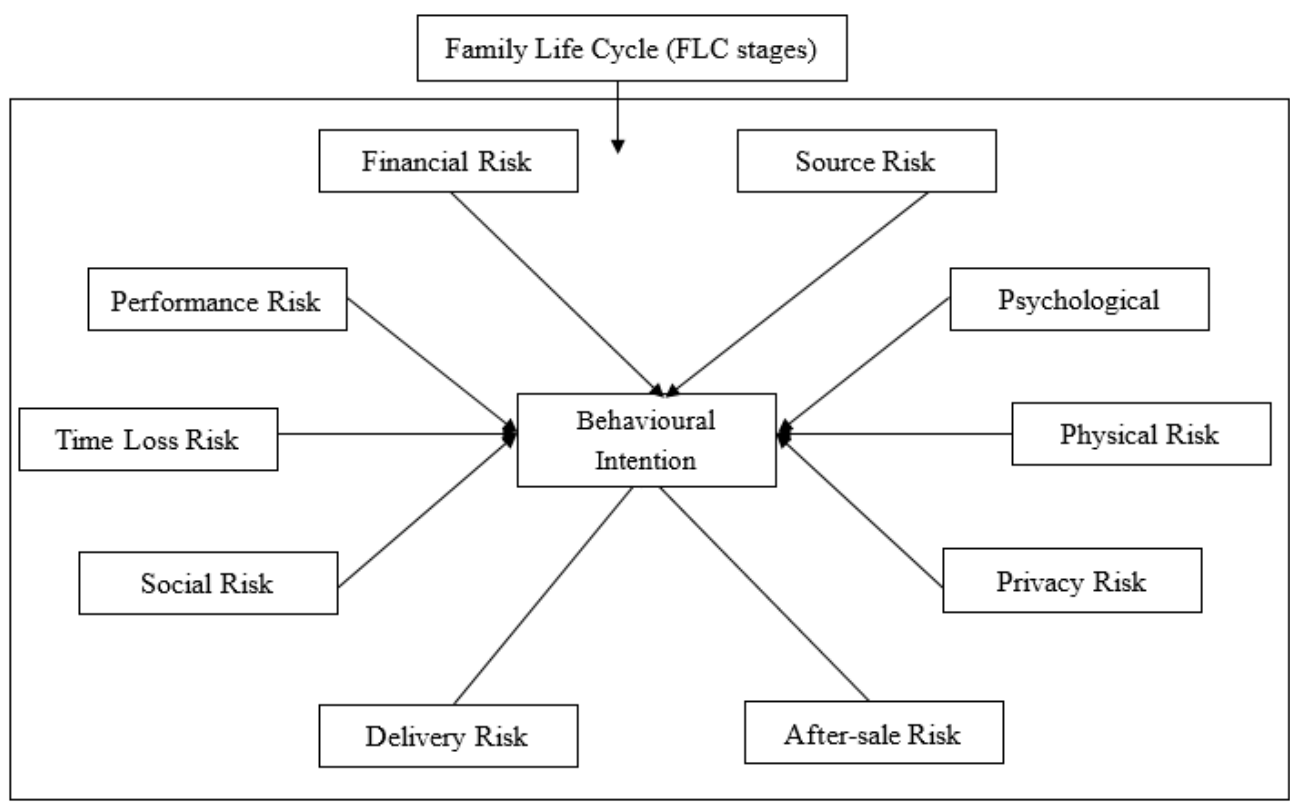

Figure 1. Proposed Research Model. 
1. Among the ten dimensions of perceived risk (financial risk, performance risk, time-loss risk, privacy risk, social risk, psychological risk, delivery risk, after-sale risk, source risk, physical risk), which dimensions of perceived risks are negatively associated with the purchase intention to shop online, among Indian women?

2. Does the effect of these risk dimensions on BI differ as women transcend from one FLC stage to the next?

\section{Literature Review}

\subsection{Perceived Risk}

The concept of perceived risk was introduced by [57], in which, it was defined as "consumer's perception of the uncertainty and the possible undesirable consequences of purchasing a product or service". In e-shopping, perceived risk is defined as "a belief about possible negative uncertainty from an online commerce transaction" [63]. Perceived risk has been regarded as one of the core motivators in consumer behavior. Studies have noted that the perception towards risk is much higher when shopping online than in the classical shopping channels $[7,12,18,28]$, because of the inability of the consumers to physically examine products before their purchase [64]. There is also increasing information asymmetry between buyers and sellers [27] in the e-shopping arena. Studies have emphasized that when converting customers who just search for products and/or services on the internet into effective buyers, it is important to understand and reduce their risk perception [50].

Perceived risk has been found to play a crucial role as one of the major determinants in influencing one's BI to shop via internet $[14-16,25,29,47,65]$. Perceived risk has also been to have a significant effect on other determinants of e-shopping, such as the consumers' e-shopping attitude [12,66,67], trust [24], customer satisfaction $[5,68]$ and repurchase intention [18]. Thus, perceived risk has been proven to be one of the crucial barriers to e-shopping.

\subsection{Socio-Demographics on Perceived Risk}

Socio-demographics and lifestyle-related changes have been found to play a crucial role in convincing consumers to shift from offline to online stores [7,69-71]. Several studies have found the effect of various socio-demographic factors on e-shopping perceived risks such as age [21,31,47], gender [50], education [21,31], etc. The observed between-group differences of these studies warrant further examination of customer segments based on various socio-demographic factors. This would provide more insight into differential behavioral patterns related to e-shopping.

Among various socio-demographic factors, age has been found to be an important factor that significantly influences risk perceptions of e-shopping [31]. Considering the age-based risk studies - studies on the effect of perceived risk on e-shopping behavior among young and old have given mixed results. Some studies have shown that perceived risk is an important factor that affects people of all age groups [47], and acts as a crucial factor for consumers in deciding whether to shop online [14]. Other studies have noted that while young people are aware of the risk in the online atmosphere, they are less concerned about risks and could decide to shop online for other reasons, whereas older people are more vulnerable to risk perception [50] and hence perceived e-shopping risk is a stronger determinant of purchase intentions among older adults [31].

Although age-based segmentation has remained popular, online shopping researchers have noted that, people belonging to same age-group may have different motivations and hence may not behave similarly; thus, to understand group motivations, age cannot be an appropriate way of segmenting people [71]. To resolve this, studies have focused on segmentation based on generation [69-71], instead of age. For instance, [13] found that perceived risk does not influence Gen Y e-shopping behavior, and [71] showed that the capacity to take risk is higher among Gen Y than Gen X and hence these groups are to be treated differently, especially when understanding perceived risk [26]. Recent studies on e-shopping adoption have split customers based on FLC stages [36,72], due to its 
established significant impact on time pressure and situational changes in families which has been proven to be one of the crucial factors affecting e-shopping [52,73].

\subsection{Family Life Cycle Stages}

'FLC differences' has been an important topic in consumer behavior studies for many years (survey paper by [74], but less so, in the context of e-shopping [71]). 'FLC stages' was introduced to the marketing domain by [75]. The study noted that FLC stages have a better predictive ability and explanatory power than the variable, age, and hence classifying customers according to FLC stages is likely to be more meaningful. Thereafter, many studies have been conducted in various areas, which have shown FLC stages to be a good predictor variable [74,76]. The FLC notion postulates that when a family shifts from one stage of life to the next, the roles of its members change, as a result of which, their financial position [77], lifestyle [78-80], situation at home [81,82], time pressure and stress level $[83,84]$, and leisure behavior [39,40], change. FLC stages have also been found to have significant impact on work-life balance $[41,45,84]$. In an attempt to manage these demanding life changes and new life situations, they modify many activities, and shopping is no exception [85].

Several studies have found the influence of FLC stages on shopping behavior in the offline context. Literature shows that as people move from one FLC stage to the next the frequency of shopping trips and enjoyment [86], time spent in shopping [87,88], purchase involvement and wise buying [89], out-shopping behavior [90], shopping styles, information use and decision making [91], spending behavior [92], consumer preference [93,94], expenditure patterns [95] and brand loyalty [76] change. Various shopping-related issues including arranging money for shopping, patronage patterns, and preference for proximity and convenience to reach the store have also been found to be affected by FLC stages [88]. A recent study on the effect of FLC stages on women shoppers observed that young mothers visit retail stores not only fulfil the shopping needs but also for recreation and social interaction [89]. A study by [96] found how the shopping activities like shopping habits, time spent on shopping and mode of shopping differed among mothers of infants with changes in life stages.

Along with constant emphasis from information and communication technology researchers [8,36-38], there are also studies emerging in the e-shopping arena, which have proven the significant impact of FLC stages on e-shopping behavior. For instance, [36], the technology acceptance model (TAM) posited how the perceptions, attitudes and BI towards shopping online differed across various life cycle stages among Indian women. [72] understood the mobile shopping behavior among older adults (above 55-74 years) based on their FLC stage. [44] found that young parents (30-40 years) are more inclined to shop for kids' products online; their focus is more on convenience and quality than price. [43] observed the effect of FLC stages in consumer purchase behaviour by including the FLC stages in the e-commerce recommendation system. The results of all these studies prove that FLC stages are better predictors of e-shopping behavior. While these studies have found the effect of FLC stages on motivators of e-shopping adoption among e-shoppers, studies aimed at understanding the effect of FLC stages on barriers to e-shopping among non-adopters remain scant. In order to address this research gap, this study attempts to understand the effects of FLC stages on e-shopping risk perception, which is one of the most important barriers to e-shopping.

\section{Hypotheses}

Although perceived risk is found to affect people of all age groups, preventing them from purchasing online, the effect of risk is stronger on BI among people of the older age group. As young people are aware of the presence of risk online, they are generally less concerned about it but keep shopping online for other reasons [5]. On the other hand, older adults, due to infrequent e-shopping behavior [18], develop a lower level of trust towards e-shopping sites. The utility seeking behavior in shopping, the attitude of treating service and security features separately [50] would still increase the risk perception towards e-shopping sites. Moreover, studies have noted that development of trust towards an e-shopping site does not lead to intended purchase among older adults, unless they are 
ready to overcome the perceived risk [50]. Thus, it can be assumed that later LC stages would perceive a higher level of risk towards e-shopping than early LC stages across all risk dimensions.

\subsection{Financial Risk and FLC Stages}

Concerns about security issues are highlighted predominantly as a major barrier to e-shopping adoption [97]. Older shoppers (Gen X) are not inclined towards discounts and promotions and are sophisticated in their buying behavior [98]. Furthermore, despite being less aware of financial risks involved in e-shopping compared to their younger counterparts, they tend to generally avoid risk than younger shoppers $[99,100]$. Hence the financial risk perceived by the later LC stages would be higher than the early LC stages.

Among early LC stages, studies have shown that, young families, once they have children, become financially unsteady, as compared to families with no children $[43,101]$. To balance their financial instability, they are found to be more involved in purchases and indulge in wise buying habits [75]. Studies have shown that risk perception is high when involvement during purchase is high [102]. When dealing with online transactions, there is a possibility of economic loss due to interception of information by unauthorised parties. In such a case, families with children would perceive more financial risk than families without children. In addition, families with young children have time pressure [39,93]. Time pressure has been shown to induce a stronger negative relationship between financial risk and technology adoption [103]. Hence, families with children (families with infants $(\mathrm{FN}(\mathrm{I}))$, families with preschool children (FN(PC)), families with school children (FN(SC))) are expected to perceive higher level of financial risk from e-shopping sites than families without children (newly married (NM), expecting parents (EP)).

Among later LC stages, in families with children, although dependent children grow older, they still undergo higher levels of time and financial pressure $[43,50,104]$. Studies have shown that financial [105] and time pressures [103] aggravate financial risk perception. It has also been reported that people looking for utilitarian value during purchase perceive higher levels of financial risk than people looking for hedonism [106]. Studies have noted that older women with children look more for utilitarian value from e-shopping sites than hedonic value [36], families with dependent children (families with teenage children (FN(TC)), families with adult dependents (FN(AD))) are expected to perceive higher financial risk as compared to families with no children or with independent children (families with adult independents (FN(AI)), empty nest and solitary survivors (EN\&SS)).

Hypothesis 1: The FLC stage to which a woman belongs has a significant impact on perception towards e-shopping financial risk, which in turn affects one's BI to shop online.

\subsection{Time-Loss Risk and FLC Stages}

Studies have shown that purchasing under time pressure crucially affects the perception of the risks involved in the transaction [35]. Although time-loss risk is not found to affect young online shoppers [107], with respect to groups for which, time is critical, time risk maybe an important factor affecting BI towards shopping [25]. For women, the time pressure increases as they move into the stage of parenthood $[44,83]$ and the time spent on leisure activities decrease $[39,40,108]$. Women in these households, conserve time by shopping quickly [87], avoid out-shopping [90] and prefer convenience during shopping [93]. Although the lower cost and time of acquiring information about products and services could be helpful for parents with young children who are time-constrained $[39,83,108]$, because of the uncertainty involved in e-shopping sites, the time-loss risk perception may increase $[7,18,28]$. This is because, while people with less time pressure can correct mistakes by reordering the goods, this is not always possible for time-constrained customers [35]. In addition, due to the insufficient time for searching product information with the limited cues displayed online, making the purchase would become a challenge to these heuristic decision makers [35]. Furthermore, the time-loss risk involved in waiting time for webpage downloads [109] may make 
young mothers find e-shopping to be a time-consuming activity. Hence, among early LC stages, time-loss risk may be higher among families with children (FN(I), FN(PC), FN(SC)) than families with no children (NM \& EP).

Similarly, among later LC stages, in families that involve children, work-life pressures may not decrease but change focus, due to frequent combination of teenager-parenting and eldercare $[104,110]$. In addition, the time/financial pressure has been found to continue $[43,44,50]$. Increased time/financial pressure, difficulty to search and process information with limited product cues available online $[35,70,109]$, and uncertainty involved in the new shopping channel $[18,28]$ could make families of these stages perceive a higher level of time-loss risk. However, older families with no dependent children do not have the urgency to buy products [90]. These people also sometimes experience loneliness [111,112], and they enjoy going out to shop [90]. Hence, among later LC stages, families with children (FN(TC), FN(AD)) would perceive a higher level of time-loss risk than families with independent/no children (FN(AI), EN\&SS).

Hypothesis 2: The FLC stage to which a woman belongs has a significant impact on perception towards e-shopping time-loss risk, which in turn affects her BI to shop online.

\subsection{Performance Risk and FLC Stages}

Performance risk is found to be another dominant factor that acts as a strong barrier among customers to shop online. Studies have shown that the perception towards performance risk may rely upon the type of product categories chosen. As people transcend from one FLC stage to the next, their needs change and consequently, the choice of products [36]. Thus, we expect that product risk towards online shopping site would differ based on the FLC stage to which they belong. Young people (Gen Y) are capable of accessing large amount of information, and also better understand their technical aspects [113]. They usually make purchase decisions after undertaking prior research on the topic, which enables them to make faster purchase decisions [114]. However, the processing of information and the information seeking behavior is less among older people [36] and hence with limited product cues, it would be difficult for them to assess the quality of the product [35]. Hence, the perceived product risk would be higher among later LC stages than early LC stages.

Among early LC stages, new families with no children, being young, tend to use technology as an end in itself; hence, despite risk issues they continue shopping online for various other reasons [115]. However, FLC studies have shown that once children enter families, parents get more involved in their purchases and also indulge in wise buying habits to make an efficient purchase [75]. For such parents, it would be difficult to trust a new medium of shopping that may cause both monetary/time-loss in case of defect. These people also rarely focus on price or brand but focus on style and quality [105]. Hence buying a non-branded product of high quality without a touch and feel effect becomes difficult for these parents. Although product information is available online, in general consumption situations, people under time pressure do not have sufficient time to gather all information about product attributes. Hence, they tend to process information at a faster rate and are more prone to focus on negative product information [35]. In such a case, the product risk would increase due to the uncertainty involved in online purchases $[18,28]$. When the discounts offered are high, the risk perception also increases [11,116] irrespective of age [23]. These young parents are found to buy a lot of product categories which also has significant effect on risk [66]. Many consumers perceive high correlation between price and quality [24]. Literature shows that the most attractive fact about e-shopping is the large discounts offered by sites [117]; this would increase risk perception. Hence among early LC stages, families with children ((FN(I), FN(PC), FN(SC)) would possess a higher level of risk than families without children (NM, EP).

Among later LC stages, older people are found to prefer branded products for their purchase [118]. However, the price dispersion online of the branded products and the large discounts on those products, in a new shopping medium with high level of uncertainty may make buyers skeptical about the 
quality [18]. Moreover, as people become older, the ability to process information becomes challenging and time consuming especially when combined with time pressure [83]. Thus, families with dependent children who suffer time/financial pressure may perceive higher levels of performance risk. On the other hand, once the children become independent and/or leave home, the older parents have excess spare time [119]. This makes them feel lonely and, in order to overcome the feeling of loneliness, they are found to spend more time on the internet [119] and also show interest in gathering information from websites [39]. This may help these older families without (dependent) children (FN(AI) and EN\&SS) mitigate product performance risk. Furthermore, these older families are found not to try new products/brands but stick on to those that they have been using for many years $[76,120]$. Hence among later LC stages, families with dependent children (FN(TC), FN(AD)) would perceive a higher amount of performance risk than families with no/independent children (FN(AI), EN\&SS).

Hypothesis 3: The FLC stage to which a woman belongs has a significant impact on perception towards e-shopping performance risk which in turn affects her BI to shop online.

\subsection{Social Risk and FLC Stages}

Social aspects have always played a crucial role in enhancing technology adoption. In the e-shopping domain, in particular, the effect of social influence on BI has been found to be stronger for women than men [16,35]. In a collectivistic country like India, shopping is considered as a social activity [59], where people usually build relationships, make collective purchase decisions, and share their shopping experiences. For instance, [121] showed that accepted retail formats have become popular among Indian shoppers. Social risk is perceived as high when one is not confident with the acceptance of a technology by their peer group. In India, several studies have noted that e-shopping has diffused into younger market segments while not much among older people [5]. Hence the social risk perceived by the early LC stages may be less than the later LC stages, as they are accustomed to traditional shopping formats.

Among the early LC stages, as social networks are crucial to young people [122] and most people have already adopted e-shopping sites, social risk towards e-shopping is expected to be less among all segments. Young families with no children have enough spare time and hence have extensive social networks $[82,114]$. These families are more likely to indulge in status-seeking shopping habits in order to showcase their purchasing power [123]. As e-shopping is popular among these segments (NM, $\mathrm{EP})$, social risk perceived by them would be less. Conversely, families with young children who are concerned about managing both their time and financial pressure, are found to be least concerned about society $[93,124,125]$. They are found to avoid social behavior during shopping and these parents are generally less likely to enjoy offline shopping experiences [124], preferring in-home shopping as it is focused and convenient $[93,125]$. Hence social risk perceived by families of early LC stages with/without children (NM, EP, FN(I), FN(PC), FN(SC)) would be less.

Once the women grow older, they are concerned about societal norms and acceptance [114]. They are not confident about their decisions and often look for opinions of others while purchasing products, to ensure that their choice of product is correct [1]. Hence, they are most likely to enjoy mingling with other shoppers [124]. Moreover, they look for value-oriented shopping [126]. As these women are older, very few people in their peer group would have adopted e-shopping [5], and hence they may face a lack of social assurance. Hence all later LC stages (FN(TC), FN(AD), FN(AI), EN\&SS) are expected to perceive higher levels of social risk towards OSSs.

Hypothesis 4: The FLC stage to which a woman belongs has a significant impact on perception towards e-shopping social risk which in turn affects her BI to shop online. 


\subsection{Psychological Risk and FLC Stages}

Psychological risk is associated with one's mental state to accept/adopt the new shopping medium. Diffusion of innovation theory-based studies have noted that whenever a technology enters in the market, it is the young people who adopt them first while older segments are late adopters [15]. In a similar vein, the mental acceptance of e-shopping is high among young shoppers. Hence their psychological risk perception would be less. However, older people are comfortable with traditional shopping formats and hence find e-shopping intimidating [67]; price fluctuations in e-shopping sites may reduce the trust developed towards e-shopping sites. Hence, due to the novelty of the activity, people belonging to later LC stages may mentally not be prepared to adopt to the new shopping medium and hence would perceive more psychological risk towards e-shopping than early LC stages.

Past studies have noted that decision making under time pressure increases consumers' psychological pressure, anxiety and negative emotions, causing a predisposition to avoid risk [34,127]. Families with young children are found to have high levels of time pressure $[83,108]$. These mothers are also found to be particular and concerned about their purchases [93] due to their financial pressures [43,101]. Hence families with young children (FN(I), FN(PC), FN(SC)) may perceive higher levels of psychological risk while purchasing online, than families without children (NM, EP).

Among later LC stages, studies have noted that families with grown-up children have high levels of time and financial pressure as compared to families with independent or no children $[25,69,90]$. Hence psychological pressure is expected to be high among these families. Nevertheless, as the e-shopping medium is new, even families with independent/no children would possess higher levels of psychological pressure in buying online. Age can be an additional contributor for their higher level of psychological pressure [67]. Hence, among later LC stages, all four stages (FN(TC), FN(AD), FN(AI) \& EN\&SS) would possess higher levels of psychological pressure.

Hypothesis 5: The FLC stage to which a woman belongs has significant impact on perception towards e-shopping psychological risk which in turn affects her BI to shop online.

\subsection{Source Risk and FLC Stages}

Familiarity with a website decreases the negative effect of overall perceived source risk on e-shopping behavior $[94,106]$. People in early LC stages, by virtue of being young, can get to know better online shopping sites with their friends' recommendations, thus, reducing the source risk. On the other hand, among older age groups, the number of people who shop online is smaller and hence it is difficult to identify the reliable online firms to shop. Hence, we expect source risk to be higher among later LC stages, than early LC stages.

Among early LC stages, while NM and EP are young and do not have much time and financial pressures, they can try different sources and can land on a good site [101,107]. They may get an idea from the recommendation of their peers and adopt and error method. However, time/financial pressures are higher among families with young children. When time/money saving is considered as a major incentive by these young parents [36,93], the trial and error method would be considered risky and hence source risk would be perceived as being high by these families (FN(I), FN(PC), FN(SC)).

Among later LC stages, since e-shopping has not diffused much into the older market segments, getting information through WOM also becomes difficult. Moreover, older consumers (Gen X) are incredibly loyal to companies [71]. Hence, later LC stages would find it difficult to identify a credible source to buy online. Studies have shown that there is technology transfer; parents learn using technology from their adolescent children [72]. Hence families with older children can get ideas from their children to locate credible sites [128], while EN\&SS stages would find it more difficult. Hence EN\&SS stages would perceive a higher level of source risk than older families with children (FN(TC), $\mathrm{FN}(\mathrm{AD}), \mathrm{FN}(\mathrm{AI}))$. 
Hypothesis 6: The FLC stage to which a woman belongs has a significant impact on perception towards e-shopping source risk which in turn affects her BI to shop online.

\subsection{After-Sale Service Risk and FLC Stages}

After-sale service risk is found to affect e-shopping. However, not all products require after-sale service and hence it depends more on the type of product bought online. FLC studies have shown that as people transcend from one FLC stage to the next, their needs differ and so do the products they purchase $[75,76]$. E-shopping studies have also shown that the choice of the products differs with different FLC stages $[36,43]$. Hence, the after-sale service risk towards e-shopping is also expected to differ.

Among early LC stages, families with children are found to rely upon various services to take care of their children and hence buy many appliances to keep themselves comfortable [129]. In such a case, the need for a timely after-sale service becomes essential. Moreover, because of the higher levels of involvement shown by the young parents during product purchase [75], added with their financial and time stress $[50,104]$, it is expected that families with young children would perceive higher level of after-sale service risk than families without children.

Similarly, among later LC stages, families with children continue to have time and financial pressures [43-45]. The electrical and electronic appliances used in families with children would be more compared to EN\&SS stages [129]. Hence, FN(TC), FN(AD) and FN(AI) may perceive a higher level of after-sale service risk. Although EN\&SS do not rely much upon these appliances, due to their old age, they may require timely home service, as they could be staying alone. Hence, the fear of after-sale service risk would be present among all later LC stages.

Hypothesis 7: The FLC stage to which a woman belongs has a significant impact on perception towards e-shopping after-sale service risk which in turn affects her BI to shop online.

\subsection{Delivery Risk and FLC Stages}

Delivery risk acts as one of the important challenges to e-retailers and has increased consumers' perceived risk towards e-shopping. Among early LC stages, NM and EP stages have enough discretionary time [107] and also do not face as much financial pressure [101] as families with children. However, in familial stages with young children, although delivery charges may not be a big burden, as saving time is a major incentive that these young mothers seek from online shopping sites [93], loss of goods and wrong delivery of goods may add to the existing financial and time pressures $[50,99]$. Hence, among early LC stages, families with children (FN(I), FN(PC), FN(SC)) would perceive more delivery risk than families without children (NM, EP).

During later LC stages, as the online shopping medium is new, the perception of risk related to the delivery of products would be higher than early LC stages. Among them, families with children who experience considerable time and financial pressure $[43,44]$ would perceive a higher level of delivery risk. Moreover, their familial needs are higher than EN\&SS and worn/wrong delivery would be very expensive in terms of both time and money. Hence, (FN(TC), FN(AD), FN(AI)) are found to perceive higher levels of delivery risk than EN\&SS stages.

Hypothesis 8: The FLC stage to which a woman belongs has a significant impact on perception towards e-shopping delivery risk which in turn affects her BI to shop online.

\subsection{Privacy Risk and FLC stages}

Privacy concerns are major inhibitors to e-shopping acceptance among both new and experienced users [130], especially among women as they are technophobic and less susceptible to use digital technology [100]. Studies have shown that people with online shopping experience may be aware of 
privacy risk [29]. Hence, women of early LC stages, who are aware of e-shopping, may perceive less privacy risk than later LC stages However, young people have been found to buy private products online than older people [131]. Hence, they may also perceive privacy risk online. Hence, we expect privacy risk to be perceived by both early and later LC stages.

Hypothesis 9: The FLC stage to which a woman belongs has a significant impact on perception towards e-shopping privacy risk which in turn affects her BI to shop online.

\subsection{Physical Risk and FLC Stages}

Physical risk is the risk caused to the body due to the usage of a product. Studies have shown that young people are tech savvy and technology is their first hand and second brain [70]. Hence, early LC stages, who use internet, not only for e-shopping but also for other purposes [115] may not find physical risks to be problematic.

However, women of later LC stages are older. They are neither familiar with computers nor are they tech savvy [5]. Hence, usage of computer for the purpose of shopping may cause adverse effect on their health, adding to their already existing physical issues due to age [132]. Hence, physical risk is expected to be higher among later LC stages than the early LC stages.

Hypothesis 10: The FLC stage to which a woman belongs has a significant impact on perception towards e-shopping physical risk which in turn affects her BI to shop online.

\section{Research Methodology}

\subsection{Participants}

The sample data consisted of female respondents from selected metropolitan cities of India, owing to the high internet diffusion rate in these cities [3]. To participate in the survey, it was ensured that the respondents met the following criteria: The women respondents were those:

- Who have never shopped online, as that would exactly replicate the risks hinder them from shopping online;

- Residing in selected metropolitan cities of India (Chennai, Bangalore, Hyderabad, Mumbai, and Pune) and;

- Living in nuclear families since the nuclear family system predominantly exists in metropolitan cities of India [133]. Furthermore, it is believed that time and work pressures are higher in nuclear families than in extended/joint families, which would affect e-shopping behavior.

- Who have remained in that particular FLC stage for the past 6 months to ensure buying behavior of that particular stage.

\subsection{Data Collection Instrument}

This study is non-experimental and quantitative in nature. The study used offline mode for data collection. Standardized self-report questionnaires were used to collect data, which had two sections. It began with the administration of screening question to respondents to ascertain if they have had any prior e-shopping experience. If the answer was no, the respondent proceeded with the questionnaire. Section 1 focused on the demographic profile of the respondent and collected details about family-related information including respondent's age, spouse's age and employment status, age of children, information on children living with them or not, to understand the FLC stage to which they belonged. Section 2 captured the perception towards e-shopping perceived risk dimensions and BI. The [134] scale was used to measure performance risk (three items), financial risk (three items), time-loss risk (three items), psychological risk (three items), source risk (three items), physical risk (three items) and [60] scale was used to measure social risk (three items), privacy risk (three items), delivery risk (three items), after-sale risk (three items) which consisted of a total of 33 scale items 
measured on a seven point Likert scale anchored by "strongly disagree" to "strongly agree" [135]. As the questionnaire (Appendix A-Table A1) has not been tested in India, a pilot study was conducted by collecting data from 10 samples across all segments. Following this, full-fledged data collection was made.

\subsection{Data Collection Procedure}

Data is gathered via offline mode. We met respondents directly at home. We preferred society/apartments as it is easy to meet many respondents at a time. The society/apartment head is contacted and explained with the data collection process and with their support, the hard copies of the samples are distributed to all the houses in the apartments. Gifts and rewards are announced to encourage participation. We requested the samples to participate in the survey staying at home. The questionnaires are collected from their homes after three days.

Data collection was made over a period of four months in five metro-cities, i.e., Chennai, Bangalore, Hyderabad, Mumbai, and Pune, in order to have a wider variety of population. The study sought 100 filled questionnaires from each FLC stage. Respondents were met directly at home/apartments and requested to participate in the survey. The homes and apartments were chosen in such a way that it covered the major areas of the cities. Gifts worth Rs. A total of 30 were announced to all participants. Additionally, a lucky prize worth Rs. 1000 was announced for three participants to improve the participation rate. Respondents were given a time of three days to complete the questionnaire.

Two rounds of data collection were carried out. The first round was based on the convenience sampling method. Homes/apartments located in different parts of the five metro-cities were chosen and around 3500 respondents meeting the study criteria were requested to participate in the survey. Finally, 725 respondents agreed to participate in the survey in Round 1. After excluding incomplete questionnaires and treating responses with a few missing values using the AMOS maximum likelihood method, 673 usable responses were obtained. Of the received responses, $53 \%$ of the respondents were in early LC stages (357), and 47\% were there in later LC stages (316). To obtain an adequate number of required samples, a second round of data collection was carried out.

The second round was based on both convenience and snowball sampling. A total of 1685 participants were identified through snowball sampling, with the help of the respondents who participated in Round 1, along with convenience sampling. All participants in Round 1 were requested to suggest potential respondents from nearby areas after they completed the survey. With the information received, data was collected from these participants and also through our own search. This resulted in 349 responses, out of which 240 were usable. Among them, 56\% belonged to early LC stages (143) and $44 \%$ belonged to later LC stages (97).

A total of 913 usable responses were received: 500 were in early LC stage and 413 were in later LC stage. When split based on FLC stages, there were 103 NM, 87 EP, 103 FN(I), 102 FN(PC), 105 FN(SC), $105 \mathrm{FN}(\mathrm{TC}), 105 \mathrm{FN}(\mathrm{AD}), 104 \mathrm{FN}(\mathrm{AI}), 99 \mathrm{EN} \& \mathrm{SS}$. This sample size is larger than that used in previous studies [42]. We then proceeded with data analysis.

\subsection{Sample Demographics}

Table 3 shows the sample demographics. The respondents were in the ages of 21-62 years. The average age of respondents was about 43 years. In terms of employment status, $34 \%$ of women were employed full time, $25 \%$ were part time or work-from-home employees and $41 \%$ were housewives. A total of $28 \%$ of women had completed their post-graduation, $35 \%$ had under-graduation degree, $27 \%$ had higher secondary education, and the remaining $10 \%$ had below higher secondary education level. This is similar to the observation of previous studies that women who have not shopped online are unemployed and less educated $[53,136]$. 
Table 3. Sample demographics.

\begin{tabular}{|c|c|c|c|c|c|c|c|c|c|}
\hline FLC Stages & NM & EP & FN(I) & FN(PC) & FN(SC) & FN(TC) & FN(AD) & FN(AI) & EN\&SS \\
\hline No. of Samples & 103 & 87 & 103 & 102 & 105 & 105 & 105 & 104 & 99 \\
\hline \multicolumn{10}{|c|}{ Age (\%) } \\
\hline 25 or below & 33 & 27 & 25 & 9 & Nil & Nil & Nil & Nil & Nil \\
\hline $26-30$ & 37 & 40 & 27 & 22 & 4 & Nil & Nil & Nil & Nil \\
\hline $31-35$ & 30 & 32 & 33 & 38 & 28 & Nil & Nil & Nil & Nil \\
\hline $36-40$ & Nil & 1 & 15 & 29 & 34 & 14 & 7 & Nil & Nil \\
\hline $41-45$ & Nil & Nil & Nil & 2 & 25 & 27 & 29 & 24 & 29 \\
\hline $46-50$ & Nil & Nil & Nil & Nil & 9 & 41 & 42 & 38 & 32 \\
\hline Above 50 & Nil & Nil & Nil & Nil & Nil & 18 & 27 & 42 & 38 \\
\hline \multicolumn{10}{|c|}{ Education (\%) } \\
\hline PG & 22 & 48 & 38 & 34 & 27 & 20 & 22 & 23 & 22 \\
\hline UG & 64 & 32 & 41 & 32 & 31 & 30 & 24 & 27 & 25 \\
\hline HSC & 14 & 10 & 21 & 33 & 33 & 34 & 33 & 34 & 30 \\
\hline Below HSC & Nil & Nil & Nil & Nil & 9 & 16 & 21 & 16 & 23 \\
\hline \multicolumn{10}{|c|}{ Employment status (\%) } \\
\hline Full Time & 24 & 19 & 18 & 21 & 33 & 47 & 51 & 42 & 52 \\
\hline $\begin{array}{l}\text { Part Time/Work } \\
\text { from Home }\end{array}$ & 32 & 33 & 29 & 37 & 33 & 18 & 17 & 15 & 10 \\
\hline Not Working & 44 & 48 & 56 & 42 & 34 & 35 & 32 & 43 & 38 \\
\hline
\end{tabular}

\subsection{Data Analysis}

As recommended by [137], a three-step approach was adopted to analyze the collected data.

- Preliminary tests: First, all measurement models were checked for their psychometric properties-the reliability and validity. To do this, Smart PLS 3.0 software package was used, as it is an extensively accepted variance-based, descriptive and prediction-oriented approach in structural equation modelling [138]. To ensure the data were free from common method bias, Harman's single factor test was conducted, using SPSS 21.0.

- Structural model: To measure the relationship among the perceived risk dimensions and BI across FLC stages, partial least square structural equation modelling (PLS-SEM) was used as it is an appropriate technique for studies with small sample sizes and models with multiple relationships [139].

- Multi-group analysis (MGA): To know if there were significant group differences across FLC stages in the dimensions of perceived risk and BI relationship, PLS-MGA was carried out as it is considered to be the simple but robust method [138].

\section{Results and Discussion}

\subsection{Preliminary Tests}

To assess the measurement model, the data were checked for reliability and validity. Reliability was checked with composite reliability (CR) values. All the $C R$ values were above 0.7 (Appendix A-Table A2), meeting the threshold requirement thus fulfilling the reliability test [140].

After the reliability test, the data was tested for its validity-both in terms of convergent and discriminant properties. Convergent validity of the constructs were tested with two values [141]; (i) factor loadings, and (ii) average variance extracted (AVE). The factor analysis results showed factor 
loadings of items on the constructs. All items had factor loadings above the recommended level of 0.70, on their corresponding constructs, thus indicating good convergent validity (Appendix A-Table A3). Similarly, all the AVEs ranged from 0.676 to 0.807 , which exceeded the recommended level of 0.50 (Appendix A-Table A2). This shows that more than one half of the variances observed in the items were accounted for by their hypothesized constructs. Thus, both conditions for convergent validity were satisfied.

Following this, to check discriminant validity of the data, the shared variances between factors were compared with the AVE of the individual factors [141]. The result showed that the AVE of the individual factors, were higher than the shared variances between factors, confirming discriminant validity. Further, the factor analysis result showed that factor loading on the respective construct was larger than its loadings on all other constructs, and there was no cross-factor loadings (Appendix A-Table A3), indicating good discriminant validity [142]. Thus, the measurement model demonstrated adequate reliability, convergent validity and discriminant validity.

Then the 'Harman's one-factor' common method bias test was conducted. The un-rotated principal component analysis including eleven factors counts for $37 \%$ of the total variance, lower than the cut-off value of $50 \%$, indicating that the data is free from common method bias.

\subsection{Structural Model}

Once the data satisfied the reliability and validity tests, the structural model was tested to confirm the hypothesized causal relationships among the constructs under study. This study proceeded to test the path significances using a bias-corrected bootstrapping re-sampling technique with 5000 sub-samples [139]. The path coefficients (beta values) indicated the strengths of the relationships between constructs. Paths with $\mathrm{t}$-values greater than or equal to 1.96 with a significance level of 0.05 [16] was considered to be significant relationship. $R^{2}$ value indicates the overall predictability of the model.

Baseline model testing: Overall results

As shown in Figure 2, the results of PLS analysis showed that, of the ten dimensions of perceived risk, only five dimensions have significant negative effect on BI to shop online. The directions of the relationships (negative effect) are in accordance with the findings observed in other studies [9-18], and the meta-analysis by [19]. Factors in order of relative importance affecting BI to shop online were performance risk, social risk, time-loss risk, psychological risk and source risk while financial risk, after-sale risk, physical risk, delivery risk and privacy risk were found to have insignificant effects [60]. Checking $R^{2}$ values, perceived risk predicted $75.7 \%$ of intention. Thus, it confirmed the model validity by meeting the reasonable criteria (above 0.19 ) to confirm the model validity [143].

Across all relationships, performance risk was more influential in affecting BI to shop online, than any other risk dimensions (twice as influential as the social risk-the second ranking risk dimension). This is similar to the results observed in several previous studies [24,28,94]. Following this, social risk and time-loss risk were found to play dominant roles. This is also in line with the results observed in past studies $[24,25,28,33]$. However, some studies have also shown that social risk and time-loss risk had insignificant effect on BI to shop online in certain developing countries $[60,140]$. However, as far as e-shopping in India is concerned, social risk and time-loss risk continue to play an important role in affecting e-shopping behavior among women. The reason for social risk to show a significant effect may be that women in India buy in groups and enjoy group memberships. When one shops online, one may feel insecure that she may be separated from the group. In a similar vein, the significant effect of time-loss risk on e-shopping BI may be due to the time constraints that Indian women have; due to excessive time spent on taking care of children and household responsibilities than men. Hence losing time may be of great concern to them. Psychological risk was found to play a dominant effect. This may be attributed to the fact that e-shopping is in nascent stage in India and most women are used to traditional shopping formats. 
Financial risk was also found to be an important barrier for e-shopping [12,94,106]. The results of this study showed insignificant effect. A similar result was also observed in a previous study conducted in China [144]. The reason for financial risk being insignificant maybe because customers prefer the cash on delivery mode of payment to online payments in India [2] due to poor internet security. Studies have noted that the perception towards financial risks differed widely with culture and e-shopping adoption rate [60]. Privacy risk was found in earlier studies to be a major deterrent affecting e-shopping BI particularly in collectivist cultures [145]. However, our study showed an insignificant effect of privacy risk on e-shopping BI. Studies have shown that except for expensive products, privacy risk did not have a significant effect on others [29]. As purchase of low-ticket items is more popular in India than the purchase of expensive goods, privacy risk would not have shown a positive effect. Moreover, earlier studies have shown that women are concerned about privacy and hence take all necessary measures to protect their privacy [130]. Hence, women would be proactive in protecting their privacy while other risks which are beyond their control would show a stronger effect. Alternately, just mitigating privacy and security risk on e-shopping, would not make one shop online. Privacy and security maybe the basic things expected by e-shoppers. It may be a hygienic factor as noted by Herzberg's theory, the absence of which would affect adoption of e-shopping, while its presence may not contribute to buying behavior. Physical and delivery risks were found to have insignificant effect in our study similar to the result observed in previous studies $[25,60]$.

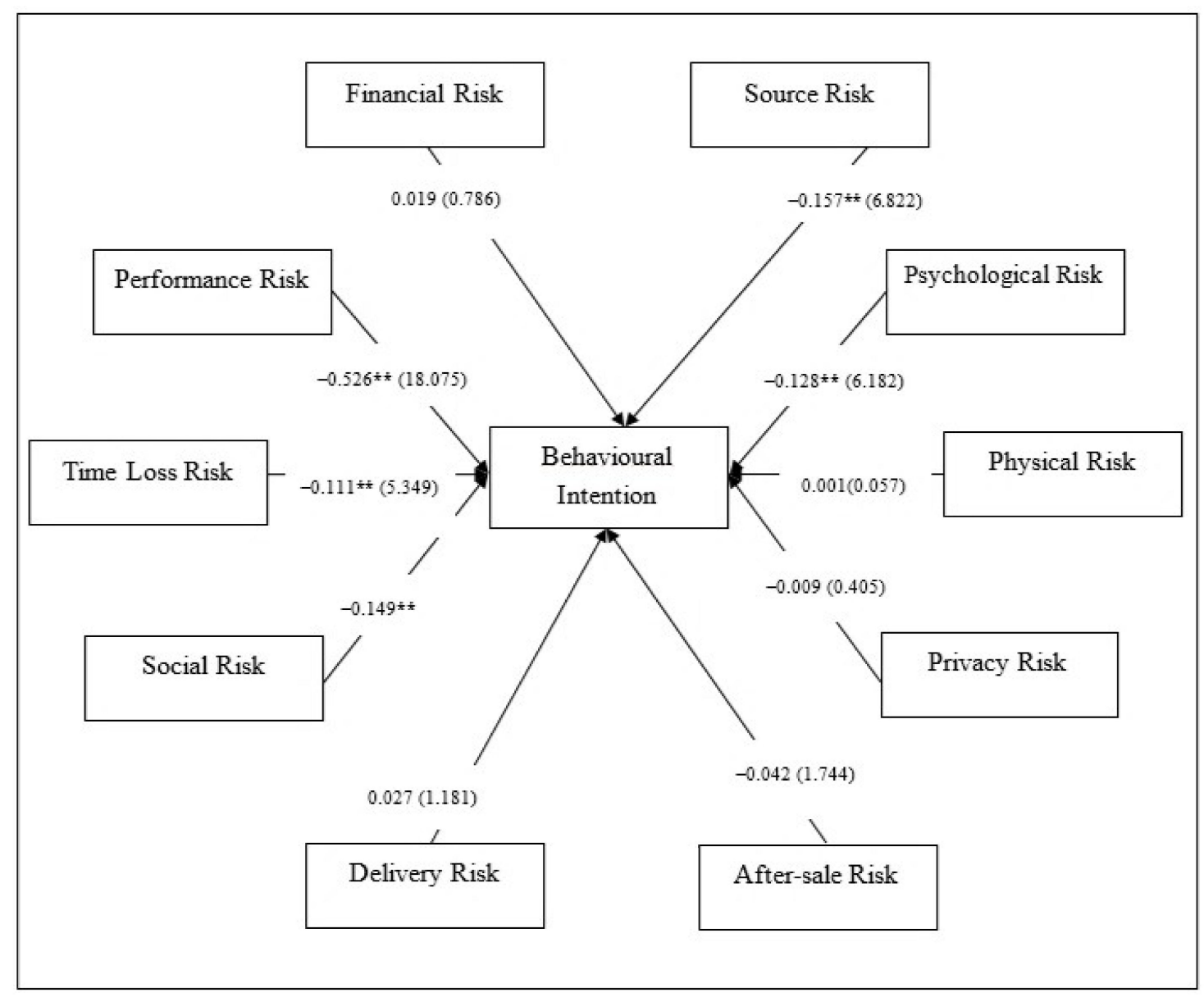

Figure 2. Structural Equation Modelling (SEM) Analysis of the Research Model. ${ }^{* *}: p$-value $<0.001$.

\subsection{FLC Stage-Wise Model Testing}

Across early LC stages, of the ten dimensions of risk, only three dimensions were found to affect people of early LC stages_-performance, time-loss and after-sale (Table 4; Figure 3). 
For NM women, no other risk, except performance was found to affect e-shopping purchase intention. EP families avoid shopping online due to their strong perception of performance and after-sale service risk. Once children enter into the family, it could be observed that time-loss risk starts to play a much more crucial role than after-sale service risk (Table 4-higher $\mathrm{t}$-values) in affecting BI to shop online. In [36], the authors noted that time saving acted as an important reason for these young families with children to shop online. With this result, it is noted that the same factor also acts as a great hindrance to adopt e-shopping. Hence, it could be inferred that time-loss risk may act as a barrier before adoption, but once adopted, e-shopping offers time-saving benefit that the same acts as a strong reason to shop online. However, other risk dimensions like financial, privacy, social, source, psychological, physical, delivery were found to be insignificant in affecting early LC stages' BI to shop online.

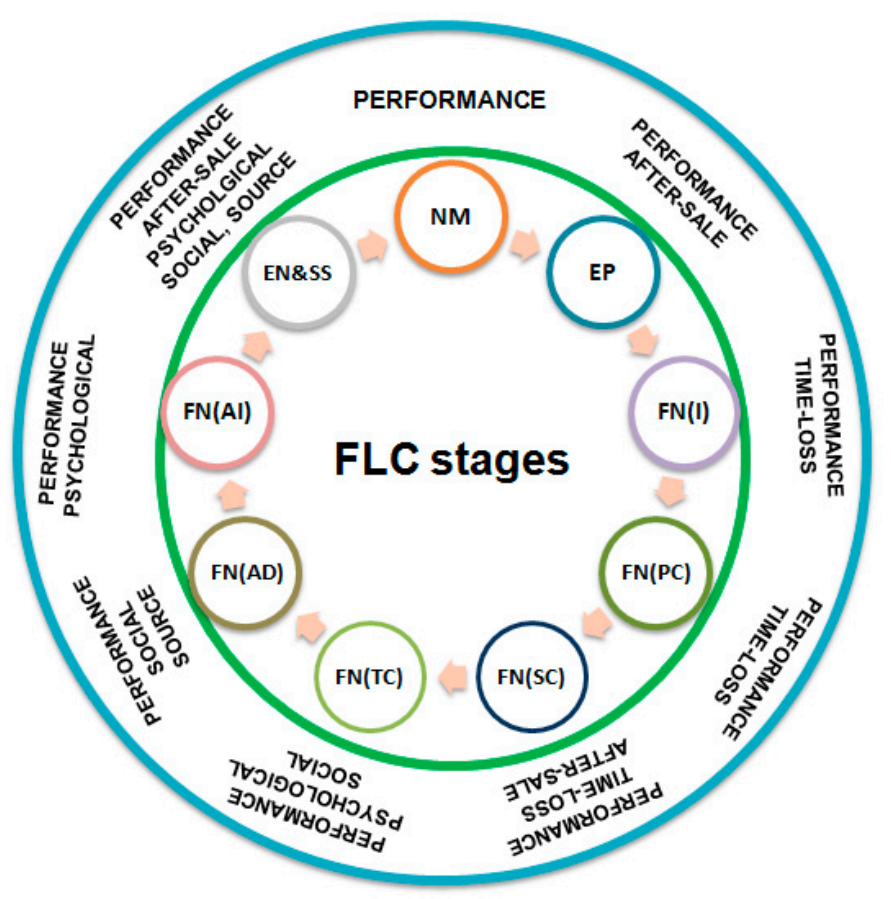

Figure 3. Risk Dimensions Influencing Women across Different FLC stages. (Based on PLS-SEM Results Shown in Table 4).

As women reach later LC stages, of the 10 risk dimensions, 5 dimensions-performance, social, source, psychological and after-sale were found to affect e-shopping BI. Performance risk continued to be a strong barrier to BI, among all later LC stages. However, the time-loss risk has been found to lose its effect while psychological risk, source risk and social risk starts gaining importance $[25,28]$. As expected, since these older families are not used to e-shopping, psychological risk of adopting a new channel and if at all adopting, confusions about the reliable site (i.e.,) source risk, all act as hindrances among these later LC stages. However, this was not applicable to all later LC stages, only 2 groups-FN(AD) and EN\&SS were found to be affected by source risk, while it was insignificant among groups FN(TC) and FN(AI). EN\&SS stages perceived after-sale service risk as these people are new to e-shopping and also stay alone. Hence, they have the most need for them. Security risk, privacy risk, time-loss risk, delivery risk, physical risk had insignificant effect on e-shopping BI among these older segments. 
Table 4. Partial least squares structural equation modelling (PLS-SEM) results.

\begin{tabular}{|c|c|c|c|c|c|c|c|c|c|c|}
\hline Beta Values & COMP & NM & EP & $\mathrm{FN}(\mathrm{I})$ & $\mathrm{FN}(\mathrm{PC})$ & FN(SC) & $\mathrm{FN}(\mathrm{TC})$ & FN(AD) & FN(AI) & EN\&SS \\
\hline Financial -> BI & 0.019 & -0.02 & -0.013 & 0.024 & 0.121 & 0.034 & 0.125 & 0.092 & -0.067 & 0.149 \\
\hline Performance-> BI & $-0.526 * *$ & $-0.600 * *$ & $-0.553 * *$ & $-0.640 * *$ & $-0.551 * *$ & $-0.505 * *$ & $-0.545 * *$ & $-0.177 * *$ & $-0.264 * *$ & $-0.591^{* *}$ \\
\hline Time-loss-> BI & $-0.111 * *$ & -0.04 & -0.017 & -0.308 * & $-0.163 *$ & $-0.173 *$ & -0.035 & -0.061 & -0.126 & 0.106 \\
\hline Psychological -> BI & $-0.128 * *$ & -0.005 & -0.002 & -0.043 & 0.03 & -0.089 & $-0.147^{*}$ & -0.14 & $-0.325 * *$ & $-0.590 * *$ \\
\hline Social -> BI & $-0.149 * *$ & -0.027 & -0.12 & -0.035 & -0.174 & 0.001 & -0.059 & $-0.373 *$ & -0.163 & -0.232 * \\
\hline Source -> BI & $-0.157^{* *}$ & -0.098 & 0.013 & -0.089 & -0.256 & -0.065 & $-0.229 * *$ & $-0.201 * *$ & -0.117 & -0.198 * \\
\hline Physical -> BI & 0.001 & 0.047 & -0.05 & -0.009 & 0.026 & -0.043 & -0.016 & -0.036 & 0.022 & 0.108 \\
\hline Privacy $->$ BI & -0.009 & -0.156 & -0.129 & -0.046 & 0.143 & -0.012 & -0.058 & -0.139 & -0.142 & 0.119 \\
\hline After sale -> BI & -0.042 & -0.166 & $-0.343 * *$ & 0.118 & -0.112 & $-0.223 *$ & -0.131 & -0.037 & 0.117 & 0.254 * \\
\hline Delivery -> BI & 0.027 & 0.103 & 0.075 & 0.082 & 0.031 & 0.027 & 0.100 & -0.125 & 0.042 & -0.027 \\
\hline T value & COMP & NM & EP & FN(I) & FN(PC) & $\mathrm{FN}(\mathrm{SC})$ & FN(TC) & FN(AD) & FN(AI) & EN\&SS \\
\hline Financial -> BI & 0.786 & 0.132 & 0.097 & 0.283 & 1.731 & 0.634 & 1.099 & 1.425 & 0.742 & 1.739 \\
\hline Performance-> BI & 18.075 & 6.176 & 3.868 & 6.361 & 4.334 & 4.261 & 5.773 & 2.469 & 3.859 & 5.110 \\
\hline Time-loss -> BI & 5.349 & 0.354 & 0.239 & 3.142 & 2.434 & 1.975 & 0.375 & 1.049 & 1.113 & 1.137 \\
\hline Psychological -> BI & 6.182 & 0.066 & 0.023 & 0.508 & 0.460 & 1.452 & 2.026 & 1.459 & 3.525 & 3.899 \\
\hline Social -> BI & 5.983 & 0.288 & 1.809 & 0.591 & 1.242 & 0.026 & 0.521 & 5.052 & 1.148 & 2.405 \\
\hline Source $->$ BI & 6.822 & 0.900 & 0.134 & 1.344 & 1.892 & 1.314 & 2.467 & 2.588 & 1.552 & 3.336 \\
\hline Physical -> BI & 0.057 & 0.518 & 0.752 & 0.116 & 0.439 & 0.414 & 0.157 & 0.331 & 0.348 & 0.846 \\
\hline Privacy $->$ BI & 0.405 & 1.301 & 1.382 & 0.730 & 1.716 & 0.253 & 0.708 & 1.234 & 1.702 & 0.848 \\
\hline After sale -> BI & 1.744 & 1.162 & 4.529 & 1.518 & 1.079 & 2.005 & 1.421 & 0.419 & 1.619 & 2.250 \\
\hline Delivery -> BI & 1.181 & 1.165 & 0.930 & 0.885 & 0.331 & 0.393 & 0.998 & 1.300 & 0.446 & 0.330 \\
\hline
\end{tabular}

** Denotes $p$ value significant at 0.01 level; * denotes $p$ value significant at 0.05 level. 


\subsection{Multi-Group Analysis}

Analyzing the PLS-MGA (Table 5), considering the significant factors in SEM analysis, it could be noted that, there were not many group differences between early and later LC stages.

While performance risk was expected to be higher among later LC stages than early, results were to the contrary. Early LC stages were found to perceive a higher level of performance risk than the later LC stages; FN(AD) and FN(AI) were particularly found to perceive a low level of performance risk. Time loss risk, as expected, is one dominant factor that was found to affect families with young children. Families FN(I) showed a significantly higher time-loss risk than families without children (NM and EP). FN(I) was also found to differ with certain later LC stages, FN(TC) and EN\&SS. In a similar vein, though not so rigorous, $\mathrm{FN}(\mathrm{PC})$ and $\mathrm{FN}(\mathrm{SC})$ perceived very high time-loss risk that it also differed with some later LC stages (EN\&SS).

Contradicting expectation, the after-sale risk perceived by early LC stages was higher than the later LC stages-FN(AI) and EN\&SS, that they differed significantly with all early LC stages except FN(I) groups. EP and FN(SC) perceived higher levels of after-sale service risk. As expected, perception of psychological risk was found to be much higher among later LC stages, especially FN(AI) and EN\&SS, that it differed with all early LC stages. EN\&SS differed with later LC stages, FN(TC) and FN(AD) as well, in that people belonging to this stage perceived a high level of psychological risk.

With regard to social risk, among later LC stages, FN(AD) perceived a higher level of social risk than any other group, that it differed with $\mathrm{FN}(\mathrm{SC})$ and FN(TC). EN\&SS also perceived a higher level of social risk, but not as high as FN(AD). However, among other later LC stages, FN(AI) or FN(TC) did not differ significantly from the early LC stages. Hence their perceived social risk was small. Source risk was found to be perceived highly by EN\&SS stages and it differed with EP and FN(SC) stages. FN(TC) and FN(AD) also differed with EP stages. However, FN(AI) did not show a significant difference with any early LC stage. 
Table 5. PLS-Multi-Group analysis (MGA) results.

\begin{tabular}{|c|c|c|c|c|c|c|c|c|c|}
\hline \multicolumn{10}{|c|}{ A. FINANCIAL RISK-BI Relationship is Indicated in Blue Colour; PERFORMANCE RISK-BI Relationship is Indicated in Orange Colour } \\
\hline & NM & EP & FN(I) & FN(PC) & FN(SC) & FN(TC) & FN(AD) & FN(AI) & EN \& SS \\
\hline NM & 0 & 0.048 & 0.039 & 0.05 & 0.095 & 0.055 & 0.423 * & $0.337^{*}$ & 0.009 \\
\hline EP & 0.007 & 0 & 0.087 & 0.002 & 0.048 & 0.008 & $0.376^{*}$ & 0.289 * & 0.039 \\
\hline FN(I) & 0.044 & 0.037 & 0 & 0.089 & 0.135 & 0.095 & 0.463 * & $0.376^{*}$ & 0.048 \\
\hline FN(PC) & 0.14 & 0.134 & 0.097 & 0 & 0.045 & 0.005 & 0.373 * & 0.287 * & 0.041 \\
\hline FN(SC) & 0.054 & 0.047 & 0.01 & 0.087 & 0 & 0.04 & 0.328 * & 0.242 * & 0.086 \\
\hline FN(TC) & 0.145 & 0.138 & 0.101 & 0.004 & 0.091 & 0 & 0.368 * & 0.282 * & 0.046 \\
\hline FN(AD) & 0.111 & 0.104 & 0.068 & 0.029 & 0.057 & 0.033 & 0 & 0.087 & 0.414 * \\
\hline FN(AI) & 0.047 & 0.054 & 0.091 & 0.188 * & 0.101 & 0.192 & 0.159 & 0 & 0.328 * \\
\hline EN \& SS & 0.169 & 0.162 & 0.125 & 0.029 & 0.115 & 0.024 & 0.058 & $0.216^{*}$ & 0 \\
\hline \multicolumn{10}{|c|}{ B. TIME-LOSS RISK-BI Relationship is Indicated in Blue Colour; PSYCHOLOGICAL RISK-BI Relationship is Indicated in Orange Colour } \\
\hline & NM & EP & FN(I) & FN(PC) & FN(SC) & FN(TC) & FN(AD) & FN(AI) & EN \& SS \\
\hline NM & 0 & 0.003 & 0.038 & 0.035 & 0.084 & 0.142 & 0.135 * & 0.32 * & $0.585^{*}$ \\
\hline EP & 0.023 & 0 & 0.041 & 0.032 & 0.087 & 0.145 & 0.138 & 0.323 * & 0.588 * \\
\hline FN(I) & $0.268^{*}$ & $0.292 *$ & 0 & 0.073 & 0.046 & 0.104 & 0.098 & $0.282 *$ & $0.547^{*}$ \\
\hline FN(PC) & 0.123 & 0.146 & 0.145 & 0 & 0.119 & 0.177 * & 0.17 & 0.355 * & $0.62 *$ \\
\hline $\mathrm{FN}(\mathrm{SC})$ & 0.133 & 0.157 & 0.135 & 0.01 & 0 & 0.058 & 0.052 & $0.236^{*}$ & $0.501^{*}$ \\
\hline FN(TC) & 0.005 & 0.018 & $0.273^{*}$ & 0.128 & 0.138 & 0 & 0.007 & 0.178 & $0.443^{*}$ \\
\hline FN(AD) & 0.021 & 0.044 & 0.247 & 0.102 & 0.112 & 0.026 & 0 & 0.184 & $0.45 *$ \\
\hline FN(AI) & 0.086 & 0.109 & 0.182 & 0.037 & 0.047 & 0.091 & 0.065 & 0 & 0.265 \\
\hline EN \& SS & 0.146 & 0.123 & $0.414^{*}$ & $0.269 *$ & $0.279 *$ & 0.141 & 0.167 & 0.232 & 0 \\
\hline
\end{tabular}


Table 5. Cont

C. SOCIAL RISK-BI Relationship is Indicated in Blue Colour; PRIVACY RISK-BI Relationship is Indicated in Orange Colour

\begin{tabular}{|c|c|c|c|c|c|c|c|c|c|}
\hline & NM & EP & FN(I) & $\mathrm{FN}(\mathrm{PC})$ & $\mathrm{FN}(\mathrm{SC})$ & $\mathrm{FN}(\mathrm{TC})$ & FN(AD) & FN(AI) & EN \& SS \\
\hline NM & 0 & 0.027 & 0.11 & 0.299 * & 0.143 & 0.098 & 0.017 & 0.014 & 0.275 \\
\hline EP & 0.094 & 0 & 0.084 & 0.272 * & 0.117 & 0.072 & 0.009 & 0.012 & 0.248 \\
\hline FN(I) & 0.008 & 0.085 & 0 & $0.189 *$ & 0.033 & 0.012 & 0.093 & 0.096 & 0.165 \\
\hline $\mathrm{FN}(\mathrm{PC})$ & 0.147 & 0.054 & 0.139 & 0 & 0.155 * & $0.2 *$ & 0.281 * & 0.284 * & 0.024 \\
\hline $\mathrm{FN}(\mathrm{SC})$ & 0.028 & 0.122 & 0.036 & 0.175 & 0 & 0.045 & 0.126 & 0.129 & 0.131 \\
\hline FN(TC) & 0.032 & 0.062 & 0.024 & 0.115 & 0.06 & 0 & 0.081 & 0.084 & 0.176 \\
\hline FN(AD) & 0.346 & 0.253 * & $0.338^{*}$ & 0.199 & 0.374 * & $0.314^{*}$ & 0 & 0.003 & 0.257 \\
\hline FN(AI) & 0.136 & 0.042 & 0.128 & 0.011 & 0.164 & 0.104 & 0.21 & 0 & 0.26 \\
\hline EN \& SS & 0.206 & 0.112 & $0.197^{*}$ & 0.058 & $0.234^{*}$ & 0.174 & 0.141 & 0.07 & 0 \\
\hline
\end{tabular}

D. SOURCE-BI relationship is indicated in Blue colour; AFTER-SALE-BI relationship is indicated in orange colour

\begin{tabular}{|c|c|c|c|c|c|c|c|c|c|}
\hline & NM & EP & FN(I) & FN(PC) & FN(SC) & FN(TC) & FN(AD) & FN(AI) & EN \& SS \\
\hline NM & 0 & 0.177 & 0.284 * & 0.054 & 0.058 & 0.034 & 0.128 & 0.283 * & $0.419 *$ \\
\hline EP & 0.111 & 0 & 0.461 * & 0.231 * & 0.12 & 0.212 * & $0.306^{*}$ & $0.46^{*}$ & 0.597 * \\
\hline FN(I) & 0.009 & 0.102 & 0 & $0.23 *$ & 0.342 * & $0.25 *$ & 0.156 & 0.001 & 0.136 \\
\hline $\mathrm{FN}(\mathrm{PC})$ & 0.158 & 0.27 & 0.167 & 0 & 0.111 & 0.02 & 0.075 & 0.229 * & $0.366^{*}$ \\
\hline FN(SC) & 0.033 & 0.078 & 0.024 & 0.191 & 0 & 0.092 & 0.094 & 0.249 * & 0.385 * \\
\hline FN(TC) & 0.131 & 0.242 * & 0.14 & 0.028 & 0.163 & 0 & 0.094 & 0.154 & 0.291 * \\
\hline FN(AD) & 0.103 & $0.214^{*}$ & 0.112 & 0.055 & 0.136 & 0.028 & 0 & 0.137 & 0.291 * \\
\hline FN(AI) & 0.019 & 0.13 & 0.028 & 0.139 & 0.052 & 0.084 & 0.084 & 0 & 0.137 \\
\hline EN \& SS & 0.1 & $0.211^{*}$ & 0.109 & 0.058 & $0.133^{*}$ & 0.031 & 0.003 & 0.081 & 0 \\
\hline
\end{tabular}


Table 5. Cont.

E. DEL-BI relationship is indicated in Blue colour; PHYSICAL-BI relationship is indicated in orange colour

\begin{tabular}{|c|c|c|c|c|c|c|c|c|c|}
\hline & NM & EP & FN(I) & $\mathrm{FN}(\mathrm{PC})$ & $\mathrm{FN}(\mathrm{SC})$ & $\mathrm{FN}(\mathrm{TC})$ & FN(AD) & FN(AI) & EN \& SS \\
\hline NM & 0 & 0.097 & 0.056 & 0.021 & 0.09 & 0.063 & 0.083 & 0.025 & 0.061 \\
\hline EP & 0.028 & 0 & 0.041 & 0.076 & 0.007 & 0.034 & 0.014 & 0.073 & 0.159 \\
\hline FN(I) & 0.02 & 0.008 & 0 & 0.035 & 0.034 & 0.007 & 0.027 & 0.031 & 0.118 \\
\hline $\mathrm{FN}(\mathrm{PC})$ & 0.071 & 0.043 & 0.051 & 0 & 0.069 & 0.042 & 0.062 & 0.004 & 0.082 \\
\hline $\mathrm{FN}(\mathrm{SC})$ & 0.076 & 0.047 & 0.055 & 0.004 & 0 & 0.027 & 0.007 & 0.065 & 0.152 \\
\hline FN(TC) & 0.003 & 0.025 & 0.018 & 0.069 & 0.073 & 0 & 0.02 & 0.038 & 0.124 \\
\hline FN(AD) & $0.228^{*}$ & 0.2 & 0.208 & 0.157 & 0.152 & 0.225 & 0 & 0.058 & 0.144 \\
\hline FN(AI) & 0.061 & 0.033 & 0.041 & 0.01 & 0.014 & 0.058 & 0.167 & 0 & 0.086 \\
\hline EN \& SS & 0.129 & 0.101 & 0.109 & 0.058 & 0.054 & 0.127 & 0.099 & 0.068 & 0 \\
\hline
\end{tabular}

${ }^{\prime *}{ }^{\prime}$ in superscript denotes the significant group differences observed between groups. 


\section{Implications}

\subsection{Theoretical Contributions}

This study contributes to a relatively unexplored field, and hence, it is a pioneering effort to understand the role of FLC stages on e-shopping perceived risk among Indian women. Additionally, the study is focused on Indian women across all LC stages, which is hardly available in the literature. This paper has made contributions to e-retail research in the following ways. First, this study considered the ten dimensions of perceived risk and analyzed their direct effects on e-shopping BI among Indian women. The results empirically proved that perceived risk dimensions have negative effects on e-shopping BI in India. While dimensions like performance, social, time-loss, psychological, source, security and after-sale service risks were found to have significant impacts on e-shopping BI among Indian women, dimensions like physical, privacy and delivery were not found to play any role. Hence, this study emphasizes on understanding the multidimensionality of perceived risk, as some dimensions of perceived risk may prove more useful than others $[6,7,10]$.

Second, using the Indian FLC stages model, this study examined how various risk dimensions affected BI towards e-shopping as women transcended from one FLC stage to the next. For this, we critically examined the ten dimensions of perceived risk across nine FLC stages. Results showed that not all the risks affected people of all FLC stages; certain risks were perceived more strongly than other risks at different stages of life. For instance, time-loss risk and after-sale risk acted as important hindrances in early LC stages, while social or source risk did not have a significant effect. As women reached the later LC stages, time-loss and after-sale risk were found to become insignificant and social and source risk became dominant. The observations of the effects of perceived risk on women shoppers across varied FLC stages showed as women transcend from one FLC stage to the next, their situations vary based on which their perceptions of the risks of e-shopping also vary. By testing the relevance of each dimension to each FLC stage, we extend our knowledge on how to decrease the perceived risk of buying online, among women across each FLC stage. Hence, this study proves that FLC based-segmentation is useful in e-shopping studies.

\subsection{Managerial Implications}

This study has the following managerial implications.

Performance risk is found to be dominantly hindering women from shopping online, across all FLC stages. Hence, measures must be taken to mitigate this risk. Detailed and complete product information, clarity regarding product guarantee and warranty policies, free returns etc., may help to some extent [22]. However, as e-shopping lacks the touch and feel effect, offering additional features like multi-dimensional view of the products with zoom functions, and product comparison features, can aid consumers in making better purchase decisions. Higher performance risk is found to increase the online search behavior [146]. Hence, facilitating quick search of products is essential. E-shopping sites may provide the right amount and quality of information at the right time to the customer at the site to promote purchase decision. Furthermore, the young generation (Gen $\mathrm{Y}$ ) is found to be more comfortable with brands than previous generations [147]. Hence, ensuring availability of branded items with appropriate product information may help them mitigate risk [13,70]. In addition, studies have noted that at times of purchases that involve relatively high product performance risk, along with product information, customers check the sources' trustworthiness [148]. Hence, providing such information would also be helpful.

Time-loss risk is found to affect families with young children, among early LC stages. Studies have already noted that these women are hard pressed for time and look to save time by shopping online. To reduce time-loss risk, a website that is light and also easy to navigate must be provided [36]. When subjected to time pressure, people opt for choosing branded goods to avoid risk. Hence for these groups more branded goods may be offered rather than local brands [35]. This would increase the time shoppers remain on the webpage that may end up in a purchase. After-sale risk is also found 
to affect early LC stages. Hence, e-retailers must guarantee after-sale service for young parents who are constrained in both time and money. These segments are found to buy more number of products from e-shopping sites. Thus, by guaranteeing and offering good after-sale service, a large segment of consumers could be captured.

Social risk, source risk and psychological risk play significant roles among later LC stages, in e-shopping adoption. As discussed, shopping is considered a social activity in a collectivistic country like India. Hence, to make e-shopping an accepted retail format, Indian women must be made to understand that they are not shopping online in isolation. In general, women tend to share their shopping experiences with others. Hence, actual e-shoppers can be projected as role models to potential buyers. A positive word-of-mouth strategy could help to advance and promote the benefits and awareness of the services of online shopping providers [7,33], which would build a trust towards the company. Providing clear information based on comparison of reviews along with pictures may reduce risk and increase source credibility among consumers [17]. Women are more open to social influence than men and often look for opinion of friends before making a purchase decision [11]. Hence e-retail firms must encourage customers to create WOM recommendation and actively participate in social forums that would reduce e-shopping risk perceptions [71].

With regard to security and privacy risk issues, both have insignificant effects on e-shopping BI among Indian women [149]. This does not mean the e-customers do not look for a secure transaction system. When ideas like digital India is gaining momentum, COD option will gradually be eliminated from online e shopping systems. In such a case, without a secure system, no customer will shop online. Hence, e-retailers must adopt superior encryption technology and implement buyer-friendly online security and privacy protection measures [22].

\section{Limitations and Future Research Directions}

This study is not free from limitations that offer avenues for future studies. With regard to the methodology, the risk dimensions and their effect on e-shopping adoption could be different for different product categories [29]. Hence understanding how it differs across various product segments would be helpful [20]. Moreover, perceived risk has been found to be considerably more when purchasing services than for goods [24]. Hence, a study of variations in risk perception across FLC stages when purchasing services would be informative. This study dealt with perceptions of online shopping risks by studying the non-adopters of e-shopping. However, the actual risks perceived by e-shoppers may be different and these differences must be understood. Studies have shown that when there are huge discounts, the risk perception is high. In such a case, at times of sale, the risk dimensions affecting BI may differ. This aspect must be tested [66]. While this study concentrated on one of the online activities i.e., e-shopping, future studies could focus on activities like e-banking, in order to understand e-commerce more effectively. Finally, risks are a function of involvement with the decision-making process. If this model is analyzed according to categories due to its implication, these results could be modified. Future research can test this variable in the model.

Author Contributions: Conceptualization, methodology, software, validation, formal analysis, investigation, resources, data curation, writing_-original draft preparation, writing—review and editing-R.A.; Visualization, supervision, funding acquisition-V.J.S.; Project administration-Y.H. All authors have read and agreed to the published version of the manuscript.

Funding: This research received no external funding.

Conflicts of Interest: The authors declare no conflict of interest. 


\section{Appendix A}

Questionnaire

\begin{tabular}{|c|c|c|}
\hline Item No. & Texts of Items & Source \\
\hline \multicolumn{3}{|c|}{ Ten dimensions of perceived risk } \\
\hline \multicolumn{3}{|c|}{ (a) Perceived Financial Risk } \\
\hline 1 & $\begin{array}{l}\text { I am concerned that my financial records might not be adequately protected if I } \\
\text { shop online. }\end{array}$ & \multirow{3}{*}[134]{} \\
\hline 2 & It is not safe to give my credit card number when I order online. & \\
\hline 3 & $\begin{array}{l}\text { I am concerned about the ultimate price of the on-line product because there might } \\
\text { be hidden costs. }\end{array}$ & \\
\hline \multicolumn{3}{|c|}{ (b) Perceived Performance Risk } \\
\hline 1 & $\begin{array}{l}\text { It is difficult to ascertain the characteristics of the products such as quality, size, } \\
\text { colour, and style by just looking at pictures on the Web. }\end{array}$ & \multirow{3}{*}[134]{} \\
\hline 2 & $\begin{array}{l}\text { It is difficult to feel, try or land experience the product prior to purchase during } \\
\text { online shopping. }\end{array}$ & \\
\hline 3 & $\begin{array}{l}\text { I am concerned that the product delivered may not be exactly as it appeared when } \\
\text { displayed on the computer screen. }\end{array}$ & \\
\hline \multicolumn{3}{|c|}{ (c) Perceived Time-Loss Risk } \\
\hline 1 & I would have to spend much time if I want to return online merchandise. & \multirow{3}{*}[134]{} \\
\hline 2 & $\begin{array}{l}\text { I am afraid that products purchased from online vendors will not be delivered on } \\
\text { time. }\end{array}$ & \\
\hline 3 & $\begin{array}{l}\text { I am concerned for the time lost between ordering and receiving products bought } \\
\text { over the Web. }\end{array}$ & \\
\hline
\end{tabular}

(d) Perceived Psychological Risk

1 The thought of online shopping makes me feel uncomfortable.

2 The thought of online shopping causes me to experience unnecessary tension.

Online shopping will lead to too much social isolation.

(e) Perceived Source Risk

1 It is difficult to ascertain the reliability and expertise of some online companies.

2 It is difficult to ascertain the reputation of some online companies.

3 I am concerned about the trustworthiness and believability of some online companies.

\section{(f) Perceived Physical Risk}

1 I am concerned about experiencing eyestrain because of frequent exposure to computer screen during online shopping.

2 I am concerned about viruses infecting my computer while I shop online.

3 I am concerned about getting carpal tunnel syndrome while shopping online.

(g) Perceived Social Risk

\begin{tabular}{cc}
\hline 1 & Online shopping may affect the image of people around me. \\
\hline 2 & Online products may not be recognized by relatives or friends. \\
\hline 3 & Online shopping may make others reduce their evaluation of me.
\end{tabular}




\begin{tabular}{|c|c|c|}
\hline Item No. & Texts of Items & Source \\
\hline \multicolumn{3}{|c|}{ (h) Perceived Privacy Risk } \\
\hline 1 & My personal information may not be kept safe. & \multirow{3}{*}[60]{} \\
\hline 2 & My email address may be abused by others. & \\
\hline 3 & My personal information may be disclosed to others companies. & \\
\hline \multicolumn{3}{|c|}{ (i) Perceived Delivery Risk } \\
\hline 1 & An additional fee will be charged for express delivery. & \multirow{3}{*}[60]{} \\
\hline 2 & After shopping, goods are easily lost. & \\
\hline 3 & Express delivery may be sent to the wrong place. & \\
\hline \multicolumn{3}{|c|}{ (j) Perceived After-Sale Service Risk } \\
\hline 1 & If I have problem with a product, it will be hard to contact the seller. & \multirow{3}{*}[60]{} \\
\hline 2 & It is difficult to solve commercial disputes in online shopping. & \\
\hline 3 & Products purchased online may lack an after-sales service guarantee. & \\
\hline \multicolumn{3}{|c|}{ Behavioural Intention } \\
\hline 1 & $\begin{array}{l}\text { Given a chance, in the next six months, the likelihood of shopping online is } \\
\text { high. }\end{array}$ & \multirow{3}{*}[60]{} \\
\hline 2 & I would consider shopping online. & \\
\hline 3 & My willingness to shop online is high. & \\
\hline
\end{tabular}

Table A1. Reliability test.

\begin{tabular}{cccc}
\hline & Cronbach's Alpha & CR & AVE \\
\hline Behavioral Intention & 0.800 & 0.882 & 0.714 \\
\hline Financial risk & 0.858 & 0.914 & 0.779 \\
\hline Performance risk & 0.881 & 0.926 & 0.807 \\
\hline Time-loss risk & 0.847 & 0.908 & 0.766 \\
\hline Psychological risk & 0.845 & 0.906 & 0.763 \\
\hline Social risk & 0.863 & 0.916 & 0.785 \\
\hline Privacy risk & 0.761 & 0.862 & 0.676 \\
\hline Source risk & 0.855 & 0.912 & 0.775 \\
\hline After-sale risk & 0.863 & 0.916 & 0.785 \\
\hline Delivery risk & 0.804 & 0.884 & 0.718 \\
\hline Physical risk & 0.814 & 0.889 & 0.728 \\
\hline
\end{tabular}


Table A2. Convergent validity test.

\begin{tabular}{|c|c|c|c|c|c|c|c|c|c|c|c|}
\hline & $\begin{array}{l}\text { Behavioral } \\
\text { Intention }\end{array}$ & $\begin{array}{c}\text { Financial } \\
\text { Risk }\end{array}$ & $\begin{array}{l}\text { Performance } \\
\text { Risk }\end{array}$ & $\begin{array}{c}\text { Time-Loss } \\
\text { Risk }\end{array}$ & $\begin{array}{l}\text { Psychological } \\
\text { Risk }\end{array}$ & $\begin{array}{c}\text { Social } \\
\text { Risk }\end{array}$ & $\begin{array}{c}\text { Privacy } \\
\text { Risk }\end{array}$ & $\begin{array}{l}\text { Source } \\
\text { Risk }\end{array}$ & $\begin{array}{c}\text { After-Sale } \\
\text { Risk }\end{array}$ & $\begin{array}{c}\text { Delivery } \\
\text { Risk }\end{array}$ & $\begin{array}{c}\text { Physical } \\
\text { Risk }\end{array}$ \\
\hline BI 1 & 0.842 & -0.444 & -0.654 & -0.445 & -0.453 & -0.592 & -0.277 & -0.537 & -0.437 & -0.366 & -0.403 \\
\hline BI 2 & 0.828 & -0.483 & -0.706 & -0.413 & -0.476 & -0.514 & -0.295 & -0.526 & -0.406 & -0.408 & -0.389 \\
\hline BI 3 & 0.866 & -0.465 & -0.713 & -0.426 & -0.464 & -0.603 & -0.284 & -0.534 & -0.423 & -0.391 & -0.407 \\
\hline Fin 1 & -0.500 & 0.899 & 0.550 & 0.332 & 0.358 & 0.419 & 0.355 & 0.484 & 0.323 & 0.406 & 0.348 \\
\hline Fin 2 & -0.497 & 0.885 & 0.536 & 0.393 & 0.360 & 0.434 & 0.297 & 0.431 & 0.342 & 0.393 & 0.318 \\
\hline Fin 3 & -0.456 & 0.864 & 0.506 & 0.311 & 0.326 & 0.418 & 0.27 & 0.427 & 0.316 & 0.348 & 0.310 \\
\hline Perf 1 & -0.781 & 0.54 & 0.911 & 0.445 & 0.433 & 0.554 & 0.307 & 0.534 & 0.427 & 0.427 & 0.442 \\
\hline Perf 2 & -0.710 & 0.556 & 0.903 & 0.429 & 0.445 & 0.563 & 0.291 & 0.510 & 0.458 & 0.416 & 0.463 \\
\hline Perf 3 & -0.710 & 0.527 & 0.881 & 0.369 & 0.432 & 0.538 & 0.322 & 0.479 & 0.385 & 0.436 & 0.435 \\
\hline TL 1 & -0.458 & 0.361 & 0.418 & 0.913 & 0.305 & 0.379 & 0.144 & 0.258 & 0.268 & 0.23 & 0.261 \\
\hline TL 2 & -0.435 & 0.312 & 0.396 & 0.848 & 0.298 & 0.324 & 0.174 & 0.279 & 0.216 & 0.225 & 0.255 \\
\hline TL 3 & -0.435 & 0.356 & 0.400 & 0.864 & 0.281 & 0.388 & 0.136 & 0.262 & 0.293 & 0.214 & 0.271 \\
\hline Psych 1 & -0.467 & 0.360 & 0.423 & 0.302 & 0.888 & 0.402 & 0.295 & 0.378 & 0.310 & 0.431 & 0.285 \\
\hline Psych 2 & -0.535 & 0.328 & 0.447 & 0.277 & 0.890 & 0.391 & 0.316 & 0.392 & 0.332 & 0.389 & 0.338 \\
\hline Psych 3 & -0.428 & 0.351 & 0.398 & 0.309 & 0.842 & 0.388 & 0.289 & 0.283 & 0.297 & 0.415 & 0.287 \\
\hline Social 1 & -0.627 & 0.410 & 0.539 & 0.383 & 0.417 & 0.876 & 0.22 & 0.554 & 0.456 & 0.335 & 0.412 \\
\hline Social 2 & -0.609 & 0.423 & 0.559 & 0.332 & 0.392 & 0.897 & 0.276 & 0.539 & 0.399 & 0.37 & 0.404 \\
\hline Social 3 & -0.553 & 0.445 & 0.531 & 0.392 & 0.385 & 0.885 & 0.248 & 0.537 & 0.444 & 0.391 & 0.406 \\
\hline Priv 1 & -0.292 & 0.320 & 0.310 & 0.129 & 0.257 & 0.235 & 0.828 & 0.227 & 0.360 & 0.357 & 0.287 \\
\hline
\end{tabular}


Table A2. Cont.

\begin{tabular}{|c|c|c|c|c|c|c|c|c|c|c|c|}
\hline & $\begin{array}{c}\text { Behavioral } \\
\text { Intention }\end{array}$ & $\begin{array}{c}\text { Financial } \\
\text { Risk }\end{array}$ & $\begin{array}{c}\text { Performance } \\
\text { Risk }\end{array}$ & $\begin{array}{c}\text { Time-Loss } \\
\text { Risk }\end{array}$ & $\begin{array}{c}\text { Psychological } \\
\text { Risk }\end{array}$ & $\begin{array}{c}\text { Social } \\
\text { Risk }\end{array}$ & $\begin{array}{c}\text { Privacy } \\
\text { Risk }\end{array}$ & $\begin{array}{c}\text { Source } \\
\text { Risk }\end{array}$ & $\begin{array}{c}\text { After-Sale } \\
\text { Risk }\end{array}$ & $\begin{array}{c}\text { Delivery } \\
\text { Risk }\end{array}$ & $\begin{array}{c}\text { Physical } \\
\text { Risk }\end{array}$ \\
\hline Priv 2 & -0.284 & 0.242 & 0.257 & 0.133 & 0.289 & 0.214 & 0.837 & 0.215 & 0.375 & 0.279 & 0.306 \\
\hline Priv 3 & -0.256 & 0.300 & 0.274 & 0.167 & 0.306 & 0.242 & 0.801 & 0.236 & 0.376 & 0.334 & 0.334 \\
\hline Source 1 & -0.606 & 0.457 & 0.524 & 0.272 & 0.378 & 0.542 & 0.253 & 0.907 & 0.379 & 0.468 & 0.331 \\
\hline Source 2 & -0.556 & 0.445 & 0.495 & 0.274 & 0.365 & 0.53 & 0.233 & 0.868 & 0.404 & 0.417 & 0.319 \\
\hline Source 3 & -0.491 & 0.438 & 0.472 & 0.255 & 0.324 & 0.553 & 0.237 & 0.865 & 0.390 & 0.423 & 0.325 \\
\hline Aft-sale 1 & -0.433 & 0.315 & 0.413 & 0.258 & 0.297 & 0.43 & 0.402 & 0.386 & 0.878 & 0.291 & 0.437 \\
\hline Aft-sale 2 & -0.445 & 0.320 & 0.412 & 0.226 & 0.343 & 0.426 & 0.412 & 0.410 & 0.888 & 0.301 & 0.457 \\
\hline Aft-sale 3 & -0.448 & 0.350 & 0.427 & 0.303 & 0.313 & 0.443 & 0.382 & 0.382 & 0.891 & 0.306 & 0.414 \\
\hline Deliv 1 & -0.383 & 0.389 & 0.392 & 0.259 & 0.437 & 0.378 & 0.332 & 0.442 & 0.331 & 0.85 & 0.265 \\
\hline Deliv 2 & -0.422 & 0.322 & 0.399 & 0.187 & 0.385 & 0.321 & 0.36 & 0.422 & 0.278 & 0.859 & 0.309 \\
\hline Deliv 3 & -0.358 & 0.398 & 0.417 & 0.205 & 0.371 & 0.35 & 0.304 & 0.397 & 0.249 & 0.833 & 0.260 \\
\hline Phys 1 & -0.382 & 0.344 & 0.427 & 0.235 & 0.305 & 0.376 & 0.318 & 0.336 & 0.437 & 0.286 & 0.842 \\
\hline Phys 2 & -0.442 & 0.305 & 0.442 & 0.284 & 0.296 & 0.404 & 0.313 & 0.319 & 0.414 & 0.273 & 0.867 \\
\hline Phys 3 & -0.382 & 0.297 & 0.401 & 0.243 & 0.293 & 0.396 & 0.329 & 0.290 & 0.410 & 0.288 & 0.850 \\
\hline
\end{tabular}


Table A3. Discriminant validity test.

\begin{tabular}{|c|c|c|c|c|c|c|c|c|c|c|c|}
\hline & $\begin{array}{l}\text { Behavioral } \\
\text { Intention }\end{array}$ & $\begin{array}{c}\text { Financial } \\
\text { Risk }\end{array}$ & $\begin{array}{l}\text { Performance } \\
\text { Risk }\end{array}$ & $\begin{array}{c}\text { Time-Loss } \\
\text { Risk }\end{array}$ & $\begin{array}{l}\text { Psychological } \\
\text { Risk }\end{array}$ & $\begin{array}{c}\text { Social } \\
\text { Risk }\end{array}$ & $\begin{array}{c}\text { Privacy } \\
\text { Risk }\end{array}$ & $\begin{array}{c}\text { Source } \\
\text { Risk }\end{array}$ & $\begin{array}{l}\text { After-Sale } \\
\text { Risk }\end{array}$ & $\begin{array}{c}\text { Delivery } \\
\text { Risk }\end{array}$ & $\begin{array}{c}\text { Physical } \\
\text { Risk }\end{array}$ \\
\hline Behavioral Intention & 0.845 & & & & & & & & & & \\
\hline Financial Risk & -0.549 & 0.883 & & & & & & & & & \\
\hline Performance Risk & -0.818 & 0.602 & 0.899 & & & & & & & & \\
\hline Time-loss Risk & -0.506 & 0.392 & 0.462 & 0.875 & & & & & & & \\
\hline Psychological Risk & -0.549 & 0.395 & 0.485 & 0.337 & 0.873 & & & & & & \\
\hline Social Risk & -0.675 & 0.48 & 0.614 & 0.416 & 0.45 & 0.886 & & & & & \\
\hline Privacy Risk & -0.338 & 0.349 & 0.341 & 0.173 & 0.344 & 0.28 & 0.822 & & & & \\
\hline Source Risk & -0.629 & 0.507 & 0.566 & 0.304 & 0.406 & 0.614 & 0.274 & 0.88 & & & \\
\hline After-sale Risk & -0.499 & 0.371 & 0.471 & 0.296 & 0.359 & 0.489 & 0.45 & 0.443 & 0.886 & & \\
\hline Delivery Risk & -0.459 & 0.434 & 0.475 & 0.255 & 0.47 & 0.411 & 0.393 & 0.496 & 0.338 & 0.847 & \\
\hline Physical Risk & -0.473 & 0.369 & 0.497 & 0.299 & 0.349 & 0.46 & 0.374 & 0.369 & 0.492 & 0.33 & 0.853 \\
\hline
\end{tabular}

Diagonal elements (in bold) represent the square root of the average variance extracted (AVE); off-diagonal elements are the shared variance. 


\section{References}

1. Internet Penetration Rate in India 2007-2020. Available online: https://www.statista.com/statistics/792074/ india-internet-penetration-rate/ (accessed on 15 May 2020).

2. The Rise and Growth of the Indian Retail Industry Published on 29 August 2019. Available online: https: //www.indiaretailing.com/2019/08/29/retail/the-rise-and-growth-of-the-indian-retail-industry/ (accessed on 29 April 2020).

3. Online is $1.6 \%$ of Retail Sales in India: World Bank. Available online: https://economictimes.indiatimes. com/industry/services/retail/online-is-1-6-of-retail-sales-in-india-world-bank/articleshow/72811360.cms? from $=$ mdr (accessed on 5 January 2020).

4. Ahmed, K.A.; Sathish, A.S. Determinants of Online Shopping Adoption: Meta Analysis and Review. Eur. J. Soc. Sci. 2015, 49, 483-510.

5. Natarajan, T.; Balasubramanian, S.A.; Kasilingam, D.L. The moderating role of device type and age of users on the intention to use mobile shopping applications. Technol. Soc. 2018, 53, 79-90. [CrossRef]

6. Guru, S.; Nenavani, J.; Patel, V.; Bhatt, N. Ranking of perceived risks in online shopping. Decision 2020, 47, 137-152. [CrossRef]

7. Bajaj, R.; Kumar, P. Exploring the influence of demographic factors on perceived performance risk among youth towards online shopping in Punjab. Int. J. Bus. Glob. 2019, 23, 47. [CrossRef]

8. Sharma, J.K.; Kurien, D. Perceived risk in e-commerce: A demographic perspective. NMIMS Manag. Rev. 2017, 34, 31-57.

9. Dabrynin, H.; Zhang, J. The Investigation of the Online Customer Experience and Perceived Risk on Purchase Intention in China. J. Mark. Dev. Compet. 2019, 13. [CrossRef]

10. Ariffin, S.K.; Mohan, T.; Goh, Y.-N. Influence of consumers' perceived risk on consumers' online purchase intention. J. Res. Interact. Mark. 2018, 12, 309-327. [CrossRef]

11. Mohseni, S.; Jayashree, S.; Rezaei, S.; Kasim, A.; Okumus, F. Attracting tourists to travel companies' websites: The structural relationship between website brand, personal value, shopping experience, perceived risk and purchase intention. Curr. Issues Tour. 2016, 21, 616-645. [CrossRef]

12. Mou, J.; Shin, D.-H.; Cohen, J.F. Trust and risk in consumer acceptance of e-services. Electron. Commer. Res. 2015, 17, 255-288. [CrossRef]

13. Muda, M.; Mohd, R.; Hassan, S. Online Purchase Behavior of Generation Y in Malaysia. Procedia Econ. Finance 2016, 37, 292-298. [CrossRef]

14. Hubert, M.; Blut, M.; Brock, C.; Backhaus, C.; Eberhardt, T. Acceptance of Smartphone-Based Mobile Shopping: Mobile Benefits, Customer Characteristics, Perceived Risks, and the Impact of Application Context. Psychol. Mark. 2017, 34, 175-194. [CrossRef]

15. Natarajan, T.; Balasubramanian, S.A.; Kasilingam, D.L. Understanding the intention to use mobile shopping applications and its influence on price sensitivity. J. Retail. Consum. Serv. 2017, 37, 8-22. [CrossRef]

16. Faqih, K.M. An empirical analysis of factors predicting the behavioral intention to adopt Internet shopping technology among non-shoppers in a developing country context: Does gender matter? J. Retail. Consum. Serv. 2016, 30, 140-164. [CrossRef]

17. Wu, W.Y.; Ke, C.C. An online shopping behavior model integrating personality traits, perceived risk, and technology acceptance. Soc. Behav. Personal. Int. J. 2015, 43, 85-97. [CrossRef]

18. Mortimer, G.; Hasan, S.F.E.; Andrews, L.; Martin, J. Online grocery shopping: The impact of shopping frequency on perceived risk. Int. Rev. Retail. Distrib. Consum. Res. 2016, 26, 202-223. [CrossRef]

19. Wilkes, R.E. Household life-cycle stages, transitions, and product expenditures. J. Consum. Res. 1995, 22, 27-42. [CrossRef]

20. Gupta, S.; Yun, H.; Xu, H.; Kim, H.-W. An exploratory study on mobile banking adoption in Indian metropolitan and urban areas: A scenario-based experiment. Inf. Technol. Dev. 2017, 23, 127-152. [CrossRef]

21. Panda, R.; Swar, B.N. Electronic Retailing: A Review of Determinants of 'Online Shopping Intentions' in India. Indian J. Sci. Technol. 2016, 9, 1-6. [CrossRef]

22. Alalwan, A.A.; Dwivedi, Y.K.; Rana, N.P.P.; Williams, M.D. Consumer adoption of mobile banking in Jordan: Examining the role of usefulness, ease of use, perceived risk and self-efficacy. J. Enterp. Inf. Manag. 2016, 29, 118-139. [CrossRef] 
23. Ieva, M.; De Canio, F.; Ziliani, C. Daily deal shoppers: What drives social couponing? J. Retail. Consum. Serv. 2018, 40, 299-303. [CrossRef]

24. Pappas, N. Marketing strategies, perceived risks, and consumer trust in online buying behaviour. J. Retail. Consum. Serv. 2016, 29, 92-103. [CrossRef]

25. Han, M.C.; Kim, Y. Why Consumers Hesitate to Shop Online: Perceived Risk and Product Involvement on Taobao.com. J. Promot. Manag. 2016, 23, 24-44. [CrossRef]

26. Yang, J.; Sarathy, R.; Lee, J. The effect of product review balance and volume on online Shoppers' risk perception and purchase intention. Decis. Support Syst. 2016, 89, 66-76. [CrossRef]

27. Liang, L.J.; Choi, H.C.; Joppe, M. Understanding repurchase intention of Airbnb consumers: Perceived authenticity, electronic word-of-mouth, and price sensitivity. J. Travel Tour. Mark. 2017, 35, 73-89. [CrossRef]

28. Rajini, G.; Krithika, M. Factors influencing online shopping intention: Impact of perceived risk. Adv. Nat. Appl. Sci. 2016, 10, 116-120.

29. Dai, B.; Forsythe, S.; Kwon, W.S. The impact of online shopping experience on risk perceptions and online purchase intentions: Does product category matter? J. Electr. Commerce Res. 2014, 15, 13.

30. Pelaez, A.; Chen, C.W.; Chen, Y.X. Effects of perceived risk on intention to purchase: A meta-analysis. J. Comput. Inf. Syst. 2019, 59, 73-84. [CrossRef]

31. Byrne, Z.S.; Dvorak, K.J.; Peters, J.M.; Ray, I.; Howe, A.; Sanchez, D. From the user's perspective: Perceptions of risk relative to benefit associated with using the Internet. Comput. Hum. Behav. 2016, 59, 456-468. [CrossRef]

32. Park, S.; Tussyadiah, I.P. Multidimensional Facets of Perceived Risk in Mobile Travel Booking. J. Travel Res. 2016, 56, 854-867. [CrossRef]

33. Shukla, R.K. Gender effect on customers' perception towards online shopping. BVIMSR's J. Manag. Res. 2016, 8, 25.

34. De Paola, M.; Gioia, F. Who performs better under time pressure? Results from a field experiment. J. Econ. Psychol. 2016, 53, 37-53. [CrossRef]

35. Liu, C.-W.; Hsieh, A.-Y.; Lo, S.-K.; Hwang, Y. What consumers see when time is running out: Consumers' browsing behaviors on online shopping websites when under time pressure. Comput. Hum. Behav. 2017, 70, 391-397. [CrossRef]

36. Amirtha, R.; Sivakumar, V.J. Does family life cycle stage influence e-shopping acceptance by Indian women? An examination using the technology acceptance model. Behav. Inf. Technol. 2018, 37, 267-294. [CrossRef]

37. Brown, S.A.; Venkatesh, V. Model of Adoption of Technology in Households: A Baseline Model Test and Extension Incorporating Household Life Cycle. MIS Q. 2005, 29, 399-426. [CrossRef]

38. Carvalho, J.; Francisco, R.; Relvas, A.P. Family functioning and information and communication technologies: How do they relate? A literature review. Comput. Hum. Behav. 2015, 45, 99-108. [CrossRef]

39. Frey, R.M.; Xu, R.; Ilic, A. Mobile app adoption in different life stages: An empirical analysis. Pervasive Mob. Comput. 2017, 40, 512-527. [CrossRef]

40. Passias, E.J.; Sayer, L.; Pepin, J.R. Who experiences leisure deficits? Mothers' marital status and leisure time. J. Marriage Fam. 2017, 79, 1001-1022. [CrossRef]

41. Wells, W.D.; Gubar, G. Life cycle concept in marketing research. J. Mark. Res. 1966, 3, 355-363. [CrossRef]

42. Allen, T.D.; Finkelstein, L.M. Work-family conflict among members of full-time dual-earner couples: An examination of family life stage, gender, and age. J. Occup. Health Psychol. 2014, 19, 376-384. [CrossRef]

43. Jiang, P.; Zhu, Y.; Zhang, Y.; Yuan, Q. Life-stage Prediction for Product Recommendation in E-commerce. In Proceedings of the 21th ACM SIGKDD International Conference on Knowledge Discovery and Data Mining-KDD'15, Sydney, Australia, 10-13 August 2015; Association for Computing Machinery (ACM): New York, NY, USA, 2015; pp. 1879-1888.

44. Sondhi, N. Empirical analysis of online purchase of kid's products by urban Indian parents. Int. J. Electr. Mark. Retail. 2015, 6, 214-238. [CrossRef]

45. Erickson, J.J.; Martinengo, G.; Hill, E.J. Putting work and family experiences in context: Differences by family life stage. Hum. Relat. 2010, 63, 955-979. [CrossRef]

46. Law, M.; Kwok, R.C.-W.; Ng, M. An extended online purchase intention model for middle-aged online users. Electron. Commer. Res. Appl. 2016, 20, 132-146. [CrossRef]

47. Lian, J.-W.; Yen, D.C. Online shopping drivers and barriers for older adults: Age and gender differences. Comput. Hum. Behav. 2014, 37, 133-143. [CrossRef] 
48. Trinh, G.; Wright, M. The Relationship between Household Lifecycle and Brand Loyalty. Adv. Consum. Res. 2014, 42. [CrossRef]

49. Macedo, I.M. Predicting the acceptance and use of information and communication technology by older adults: An empirical examination of the revised UTAUT2. Comput. Hum. Behav. 2017, 75, 935-948. [CrossRef]

50. Chakraborty, R.; Lee, J.; Bagchi-Sen, S.; Upadhyaya, S.; Rao, H.R. Online shopping intention in the context of data breach in online retail stores: An examination of older and younger adults. Decis. Support Syst. 2016, 83, 47-56. [CrossRef]

51. Arora, N.; Aggarwal, A. The role of perceived benefits in formation of online shopping attitude among women shoppers in India. South Asian J. Bus. Stud. 2018, 7, 91-110. [CrossRef]

52. Fang, J.; Wen, C.; George, B.; Prybutok, V.R. Consumer heterogeneity, perceived value, and repurchase decision-making in online shopping: The role of gender, age, and shopping motives. J. Electr. Commerce Res. 2016, 17, 116.

53. Raman, P. What Women Want? An Analysis of Demographics and Different Factors Influencing Online Shopping in India. J. Bus. Manag. 2017, 23, 82-118.

54. Sengupta, S.; Dutta, U.S.; Sen, A. Re-inventing Household Shopping Patterns and Buying Roles: Exploring the "New Women" in Urban India. AKADEMOS 2018, 263-284.

55. Siddiqui, W. Study on buying behavior of men and women. Imp. J. Interdiscip. Res. 2016, 2, 664-667.

56. Piasna, A.; Plagnol, A. Women's job quality across family life stages: An analysis of female employees across 27 European countries. Soc. Indicators Res. 2018, 139, 1065-1084. [CrossRef]

57. Bauer, A.R. Consumer Behavior as Risk Taking. In Dynamic Marketing for a Changing World; Hancock, R.S., Ed.; American Marketing Association: Chicago, IL, USA, 1960; pp. 389-398.

58. Jacoby, J.; Kaplan, L.B. The Components of Perceived Risk; ACR Special Volumes; Association for Consumer Research: Chicago, IL, USA, 1972.

59. Lim, J.; Beatty, S.E. Factors affecting couples' decisions to jointly shop. J. Bus. Res. 2011, 64, 774-781. [CrossRef]

60. Al-Rawad, M.I.; Al Khattab, A.; Al-Shqairat, Z.I.; Krishan, T.A.; Jarrar, M.H. An Exploratory Investigation of Consumers' Perceptions of the Risks of Online Shopping in Jordan. Int. J. Mark. Stud. 2015, 7. [CrossRef]

61. Ziggers, G.W.; Henseler, J. The reinforcing effect of a firm's customer orientation and supply-base orientation on performance. Ind. Mark. Manag. 2016, 52, 18-26. [CrossRef]

62. Dillon, S.; Buchanan, J.; Al-Otaibi, K. Perceived risk and online shopping intention: A study across gender and product type. Int. J. E-Bus. Res. 2014, 10, 17-38. [CrossRef]

63. Kim, J.; Forsythe, S. Factors affecting adoption of product virtualization technology for online consumer electronics shopping. Int. J. Retail. Distrib. Manag. 2010, 38, 190-204. [CrossRef]

64. Chiu, C.-M.; Wang, E.T.G.; Fang, Y.-H.; Huang, H.-Y. Understanding customers' repeat purchase intentions in B2C e-commerce: The roles of utilitarian value, hedonic value and perceived risk. Inf. Syst. J. 2012, 24, 85-114. [CrossRef]

65. Tanis, M.; van der Louw, M.; Buijzen, M. From empty nest to Social Networking Site: What happens in cyberspace when children are launched from the parental home? Comput. Human Behav. 2017, 68, 56-63. [CrossRef]

66. Ahmadinejad, B.; Asli, H.N.; Ahmadinejad, S. The Effect of Perceived Risk in Discount Condition on the e-Purchase Intention. MAYFEB J. Bus. Manag. 2017, 2, 1-8.

67. Khare, A.; Sadachar, A. Collective Self-Esteem and Online Shopping Attitudes among College Students: Comparison between the U.S. and India. J. Int. Consum. Mark. 2014, 26, 106-121. [CrossRef]

68. Stone, G.P.; Form, W.H. The Local Community Clothing Market: A Study of the Social and Social Psychological Contexts of Shopping; Agricultural Experiment Station, Department of Sociology and Anthropology, Michigan State University: East Lansing, MI, USA, 1957.

69. Chauke, X.D.; Dhurup, M. A Generation X Cohort Analysis of E-shoppers: Satisfaction, Loyalty and Repurchase Intentions in a Developing Country. J. Soc. Sci. 2017, 52, 145-154. [CrossRef]

70. Bilgihan, A. Gen Y customer loyalty in online shopping: An integrated model of trust, user experience and branding. Comput. Hum. Behav. 2016, 61, 103-113. [CrossRef]

71. Lissitsa, S.; Kol, O. Generation X vs. Generation Y-A decade of online shopping. J. Retail. Consum. Serv. 2016, 31, 304-312. [CrossRef] 
72. Kuoppamäki, S.-M.; Taipale, S.; Wilska, T.-A. The use of mobile technology for online shopping and entertainment among older adults in Finland. Telematics Informatics 2017, 34, 110-117. [CrossRef]

73. Overby, J.W.; Lee, E.J. The effects of utilitarian and hedonic online shopping value on consumer preference and intentions. J. Bus. Res. 2006, 59, 1160-1166. [CrossRef]

74. Bauer, M.; Auer-Srnka, K.J. The life cycle concept in marketing research. J. Hist. Res. Mark. 2012, 4, 68-96. [CrossRef]

75. Wang, J.C.; Chang, C.H. How online social ties and product-related risks influence purchase intentions: A Facebook experiment. Electr. Commerce Res. Appl. 2013, 12, 337-346. [CrossRef]

76. Thakur, R.; Srivastava, M. Adoption readiness, personal innovativeness, perceived risk and usage intention across customer groups for mobile payment services in India. Internet Res. 2014, 24, 369-392. [CrossRef]

77. Xiao, J.J.; Yao, R. Consumer debt delinquency by family lifecycle categories. Int. J. Bank Mark. 2014, 32, 43-59. [CrossRef]

78. Rapoport, R.; Rapoport, R.N. Leisure and the Family Life Cycle; Routledge: London, UK, 2019.

79. Oghlu, C.N.Z. Psychological features of changes in family lifestyle during the period of old ages and senility. Eur. Sci. Rev. 2019, 5-6.

80. Melo, K.; de Barros, S.B.; Santos, T.; De Marco, A.; Hirota, V.; de Sa, C.A. The Relationship between Family Lifestyle and Physical Activity of Children from 4 to 6 Years. Int. J. Sports Phys. Educ. 2017, 3, 12-16.

81. Ur Rahman, S.; Khan, M.A.; Iqbal, N. Motivations and barriers to purchasing online: Understanding consumer responses. South Asian J. Bus. Stud. 2018, 7, 111-128. [CrossRef]

82. Li, R.; Li, Y.-J.; Gao, X. Study on the Current Situation of Urban Empty Nest Elderly of Community Home Care and Innovation Strategy. In Proceedings of the International Conference on Human Aspects of IT for the Aged Population, Las Vegas, NV, USA, 15-20 July 2018; Springer: Cham, Switzerland, 2018; pp. 108-117.

83. Peng, L.; Zhang, W.; Wang, X.; Liang, S. Moderating effects of time pressure on the relationship between perceived value and purchase intention in social E-commerce sales promotion: Considering the impact of product involvement. Inf. Manag. 2019, 56, 317-328. [CrossRef]

84. Bennett, M.M.; Beehr, T.A.; Ivanitskaya, L.V. Work-family conflict: Differences across generations and life cycles. J. Manag. Psychol. 2017, 32, 314-332. [CrossRef]

85. Kim, E.; Park, M.-C.; Lee, J. Determinants of the intention to use Buy-Online, Pickup In-Store (BOPS): The moderating effects of situational factors and product type. Telematics Informatics 2017, 34, 1721-1735. [CrossRef]

86. Statista.com. E-Commerce Share of Total Retail Sales in India from 2014 to 2019. Available online: https: //www.statista.com/statistics/379167/e-commerce-share-of-retail-sales-in-india/ (accessed on 5 October 2019).

87. Rich, S.U.; Jain, S.C. Social class and life cycle as predictors of shopping behavior. J. Mark. Res. 1968, 5, 41-49. [CrossRef]

88. Mitchell, I. Correlates of Consumer Shopping Behaviour in the Cooperative Socialist Republic of Guyana. Soc. Econ. Stud. 1985, 34, 26-68.

89. Johnstone, M.-L.; Todd, S. Servicescapes: The role that place plays in stay-at-home mothers' lives. J. Consum. Behav. 2012, 11, 443-453. [CrossRef]

90. Darden, W.R.; Perreault, W.D., Jr. Identifying interurban shoppers: Multiproduct purchase patterns and segmentation profiles. J. Mark. Res. 1976, 13, 51-60. [CrossRef]

91. Hawks, L.K.; Ackerman, N.M. Family life cycle differences for shopping styles, information use, and decision-making. J. Fam. Econ. Issues 1990, 11, 199-219. [CrossRef]

92. Wepfer, A.G.; Brauchli, R.; Jenny, G.J.; Hämmig, O.; Bauer, G.F. The experience of work-life balance across family-life stages in Switzerland: A cross-sectional questionnaire-based study. BMC Public Health 2015, 15, 1290. [CrossRef] [PubMed]

93. Mathur, A.; Moschis, G.P.; Lee, E. Life events and brand preference changes. J. Consum. Behav. 2003, 3, 129-141. [CrossRef]

94. Mathur, A.; Moschis, G.P.; Lee, E. A longitudinal study of the effects of life status changes on changes in consumer preferences. J. Acad. Mark. Sci. 2007, 36, 234-246. [CrossRef]

95. Hong, G.-S.; Fan, J.X.; Palmer, L.; Bhargava, V. Leisure Travel Expenditure Patterns by Family Life Cycle Stages. J. Travel Tour. Mark. 2005, 18, 15-30. [CrossRef]

96. Burningham, K.; Venn, S.; Christie, I.; Jackson, T.; Gatersleben, B. New motherhood: A moment of change in everyday shopping practices? Young Consum. 2014, 15, 211-226. [CrossRef] 
97. Bezes, C. Comparing online and in-store risks in multichannel shopping. Int. J. Retail. Distrib. Manag. 2016, 44, 284-300. [CrossRef]

98. Dunne, P.; Lusch, R. Retailing, 6th ed.; Thomson Higher Education: Mason, OH, USA, 2008.

99. Lorian, C.N.; Grisham, J.R. Clinical implications of risk aversion: An online study of risk-avoidance and treatment utilization in pathological anxiety. J. Anxiety Disord. 2011, 25, 840-848. [CrossRef]

100. Michota, A. Digital security concerns and threats facing women entrepreneurs. J. Innov. Entrep. 2013, 2, 1-11. [CrossRef]

101. McNair, S.J.; Summers, B.; De Bruin, W.B.; Ranyard, R. Individual-level factors predicting consumer financial behavior at a time of high pressure. Pers. Individ. Differ. 2016, 99, 211-216. [CrossRef]

102. Keisidou, E.; Sarigiannidis, L.; Maditinos, D. Consumer characteristics and their effect on accepting online shopping, in the context of different product types. Int. J. Bus. Sci. Appl. Manag. 2011, 6, 31-51.

103. Bhattacherjee, A. Understanding Information Systems Continuance: An Expectation-Confirmation Model. MIS Q. 2001, 25, 351-370. [CrossRef]

104. Malik, R. A study of academic stress among adolescent children of working and Non-Working Mothers. Int. J. Adv. Res. Manag. Soc. Sci. 2017, 6, 38-44.

105. Reisenwitz, T.H.; Iyer, R. Differences in generation $X$ and generation Y: Implications for the organization and marketers. Mark. Manag. J. 2009, 19, 91-103.

106. De Kerviler, G.; Demoulin, N.T.M.; Zidda, P. Adoption of Proximity M-Payment Services: Perceived Value and Experience Effect (An Abstract). In Marketing at the Confluence between Entertainment and Analytics; Springer: Cham, Switzerland, 2017; pp. 275-276.

107. Roberts, K. Youth and Leisure; Routledge: London, UK, 2019.

108. Sayer, L. Parenthood and Leisure Time Disparities. In Contemporary Parenting and Parenthood: From News Headlines to New Research; ABC-CLIO: Santa Barbara, CA, USA, 2018; p. 168.

109. Smith, A.C.; Ralph, B.C.; Marty-Dugas, J.; Smilek, D. Loading ... loading ... The influence of download time on information search. PloS ONE 2019, 14, e226112. [CrossRef]

110. Rajan, S.I.; Sunitha, S.; Arya, U.R. Elder Care and Living Arrangement in Kerala. In Elderly Care in India; Springer: Singapore, 2017; pp. 95-116.

111. Fakoya, O.A.; McCorry, N.K.; Donnelly, M. Loneliness and social isolation interventions for older adults: A scoping review of reviews. BMC Public Health 2020, 20, 1-14. [CrossRef]

112. Grover, S. Loneliness: Does it need attention! J. Geriatr. Ment. Health 2019, 6, 1. [CrossRef]

113. Rahulan, M.; Troynikov, O.; Watson, C.; Janta, M.; Senner, V. Consumer behavior of generational cohorts for compression sportswear. J. Fashion Mark. Manag. 2015, 19, 87-104. [CrossRef]

114. Parment, A. Generation Y vs. Baby Boomers: Shopping behavior, buyer involvement and implications for retailing. J. Retail. Consum. Serv. 2013, 20, 189-199. [CrossRef]

115. Nawaz, I.Y. Characteristics of Millennials and Technology Adoption in the Digital Age. In Leveraging Computer-Mediated Marketing Environments; IGI Global: Hershey, PA, USA, 2020; pp. 241-262.

116. Nakhata, C.; Kuo, H.-C. Consumer avoidance of specially priced items during social coupon redemption. J. Retail. Consum. Serv. 2017, 34, 287-293. [CrossRef]

117. Assocham India. Over 120 million Indian Consumers Expected to Shop Online in 2018: ASSOCHAM-Resurgent Study. Available online: http://www.assocham.org/newsdetail.php?id=6866 (accessed on 11 June 2020).

118. Centro.net. Get to Know Gen X, A Small but Mighty Generation. 2015. Available online: https://www.centro. net/blog/generation-x-the-small-but-mighty-generation/ (accessed on 16 May 2020).

119. Tandon, U.; Kiran, R.; Sah, A.N. The influence of website functionality, drivers and perceived risk on customer satisfaction in online shopping: An emerging economy case. Inf. Syst. e-Bus. Manag. 2018, 16, 57-91. [CrossRef]

120. Phua, P.; Kennedy, R.; Trinh, G.; Page, B.; Hartnett, N. Examining older consumers' loyalty towards older brands in grocery retailing. J. Retail. Consum. Serv. 2020, 52, 101893. [CrossRef]

121. Khare, A.; Khare, A.; Singh, S. Attracting Shoppers to Shop Online-Challenges and Opportunities for the Indian Retail Sector. J. Internet Commer. 2012, 11, 161-185. [CrossRef]

122. Hewlett, S.A.; Sherbin, L.; Sumberg, K. How Gen Y and Boomers will reshape your agenda. Harv. Bus. Rev. 2009, 87, 71-76. 
123. Eastman, J.K.; Liu, J. The impact of generational cohorts on status consumption: An exploratory look at generational cohort and demographics on status consumption. J. Consum. Mark. 2012, 29, 93-102. [CrossRef]

124. Cox, A.D.; Cox, D.; Anderson, R.D. Reassessing the pleasures of store shopping. J. Bus. Res. 2005, 58, $250-259$. [CrossRef]

125. Hand, C.; Riley, F.D.; Harris, P.; Singh, J.; Rettie, R. Online grocery shopping: The influence of situational factors. Eur. J. Mark. 2009, 43, 1205-1219. [CrossRef]

126. Kumar, A.; Lim, H. Age differences in mobile service perceptions: Comparison of Generation $Y$ and baby boomers. J. Serv. Mark. 2008, 22, 568-577. [CrossRef]

127. Saqib, N.U.; Chan, E.Y. Time pressure reverses risk preferences. Organiz. Behav. Hum. Decis. Process. 2015, 130, 58-68. [CrossRef]

128. Luijkx, K.; Peek, S.; Wouters, E. Grandma, You Should Do It-It's Cool' Older Adults and the Role of Family Members in Their Acceptance of Technology. Int. J. Environ. Res. Public Health 2015, 12, 15470-15485. [CrossRef]

129. Camacho, J.A.; Hernández-Peinado, M.; Camacho, J.A. Family, life cycle and consumption of services: The Spanish case. Serv. Ind. J. 2009, 29, 1293-1310. [CrossRef]

130. Baruh, L.; Secinti, E.; Cemalcilar, Z. Online Privacy Concerns and Privacy Management: A Meta-Analytical Review. J. Commun. 2017, 67, 26-53. [CrossRef]

131. Helsper, E.J. Gendered Internet Use Across Generations and Life Stages. Commun. Res. 2010, 37, $352-374$. [CrossRef]

132. Howdon, D.; Rice, N. Health care expenditures, age, proximity to death and morbidity: Implications for an ageing population. J. Health Econ. 2018, 57, 60-74. [CrossRef] [PubMed]

133. Forbes India. Disintegration of the Joint Family System, Emergence of Nuclear Family. Available online: http://www.forbesindia.com/blog/beyond-the-numbers/disintegration-of-the-joint-familysystem-emergence-of-nuclear-family/ (accessed on 5 May 2020).

134. Hassan, A.M.; Kunz, M.B.; Pearson, A.W.; Mohamed, F.A. Conceptualization and measurement of perceived risk in online shopping. Mark. Manag. J. 2006, 16, 138-147.

135. Gupta, A.; Arora, N. Understanding determinants and barriers of mobile shopping adoption using behavioral reasoning theory. J. Retail. Consum. Serv. 2017, 36, 1-7. [CrossRef]

136. Rao, M.B.; Hymavathi, C.L.; Rao, M.M. Factors affecting female consumer's online buying behavior. Acad. Mark. Stud. J. 2018, 22, 1-20.

137. Anderson, J.C.; Gerbing, D.W. Structural equation modeling in practice: A review and recommended two-step approach. Psychol. Bull. 1988, 103, 411. [CrossRef]

138. Zheng, L.; Favier, M.; Huang, P.; Coat, F. Chinese consumer perceived risk and risk relievers in e-shopping for clothing. J. Electr. Commerce Res. 2012, 13, 255.

139. Leguina, A. A primer on partial least squares structural equation modeling (PLS-SEM). Int. J. Res. Method Educ. 2015, 38, 220-221. [CrossRef]

140. Hair, J.F.; Ringle, C.M.; Sarstedt, M. PLS-SEM: Indeed a Silver Bullet. J. Mark. Theory Pr. 2011, 19, $139-152$. [CrossRef]

141. Fornell, C.; Larcker, D.F. Evaluating Structural Equation Models with Unobservable Variables and Measurement Error. J. Mark. Res. 1981, 18, 39. [CrossRef]

142. Chin, W.W. The partial least squares approach to structural equation modeling. Mod. Methods Bus. Res. 1998, 295, 295-336.

143. Hair, J.F.; Sarstedt, M.; Ringle, C.M.; Mena, J.A. An assessment of the use of partial least squares structural equation modeling in marketing research. J. Acad. Mark. Sci. 2012, 40, 414-433. [CrossRef]

144. Yarimoglu, E.K. Demographic differences on service quality and perceived value in private online shopping clubs. J. Strateg. Mark. 2017, 25, 240-257. [CrossRef]

145. Pham, T.L. An empirical investigation of consumer perceptions of online shopping in an emerging economy. Asia Pacific J. Mark. Logist. 2018, 30, 952-971.

146. Biswas, D.; Burman, B. The effects of product digitalization and price dispersion on search intentions in offline versus online settings: The mediating effects of perceived risks. J. Prod. Brand Manag. 2009, 18, 477-486. [CrossRef]

147. Lazarevic, V. Encouraging brand loyalty in fickle generation Y consumers. Young Consum. 2012, 13, 45-61. [CrossRef] 
148. Vijayanchali, S.S.; Gandhi, E.A. Life at elderly: A situational analysis. In Inclusive Growth in India; MJP Publisher: New Delhi, India, 2019; p. 248.

149. Gong, W.; Stump, R.L.; Maddox, L.M. Factors influencing consumers' online shopping in China. J. Asia Bus. Stud. 2013, 7, 214-230. [CrossRef]

Publisher's Note: MDPI stays neutral with regard to jurisdictional claims in published maps and institutional affiliations.

(C) 2020 by the authors. Licensee MDPI, Basel, Switzerland. This article is an open access article distributed under the terms and conditions of the Creative Commons Attribution (CC BY) license (http://creativecommons.org/licenses/by/4.0/). 